\title{
Gender mismatches under nominal ellipsis
}

\author{
Jason Merchant, University of Chicago
}

$2013^{1}$

\begin{abstract}
Masculine/feminine pairs of human-denoting nouns in Greek fall into three distinct classes under predicative ellipsis: those that license ellipsis of their counterpart regardless of gender, those that only license ellipsis of a same-gendered noun, and those in which the masculine noun of the pair licenses ellipsis of the feminine version, but not vice versa. The three classes are uniform in disallowing any gender mismatched ellipses in argument uses, however. This differential behavior of gender in nominal ellipsis can be captured by positing that human-denoting nouns in Greek, while syntactically and morphological uniform in showing a masculine/feminine contrast, do not all encode this contrast in their semantics. Under a semantic identity theory of ellipsis, the attested variation in nominal ellipses in Greek is posited to derive from the fact that nominal ellipsis has two possible sources: a nominal constituent can be elided (true ellipsis), or a null nominal proform can be used (model-theoretic anaphora).
\end{abstract}

It is well understood that the analysis of elliptical phenomena has the potential to inform our understanding of the syntax-semantics interface, as it forces the analyst to confront directly the mechanisms for generating meanings without the usual forms that give rise to them. But facts from ellipsis have an equal potential to illuminate our understanding of the structure of the lexicon. A close investigation of nominal ellipses in Greek shows that gender features are not all created equal: following the literature on gender (see Corbett 1991 and Wechsler and Zlatić 2003 for overviews), we must distinguish syntactic gender from semantic gender.

This conclusion is forced upon us by the following generalization:

\footnotetext{
${ }^{1}$ Primary thanks go to Anastasia Giannakidou for many years of discussion of these topics and for her careful and patient judgments, and to Mark Baltin for organizing and inviting me to present at the session at the LSA in Pittsburgh which provided the primary impetus to write this paper (and for his patience in its gestation). Special thanks also to the two reviewers for Lingua, whose in depth comments on the first version of this have helped me clarify my thinking in a number of places and led to a substantial rethinking of the analysis. Additional thanks to Marcela Depiante for introducing me to these topics and discussing them with me over many years, to Andrés Saab, to the students in my seminar on Romance syntax in the spring of 2010 for making me try to make sense of these facts, to audiences at the LSA, MIT, Stanford, Chicago, Paris, and the International Conference on Greek Linguistics 10 in Komotini for their comments and suggestions, and to Tasos Chatzikonstantinou, Katerina Chatzopoulou, Nikos Nestoras, and Nektarios Morakalis for judgments beyond the call of duty.
} 
(1) Gender and ellipsis generalization: When gender is variable (as on determiners, clitics, adjectives, and some nominals under certain conditions), it may be ignored under ellipsis. When gender is invariant (on nouns in argument positions, and on some nominals in predicative uses), it may not be ignored under ellipsis.

I argue that this generalization finds a relatively straightforward account in a semantic theory of ellipsis, if 'ellipsis' is in fact a heterogeneous phenomenon, following Hankamer and Sag 1976, van Craenenbroeck 2010, Baltin 2012, and many others. In other words, what appears to be a uniform set of missing elements in nominal structures in Greek has in fact two structural sources:

- PF-deletion of a nominal projection (nP or 'GenderP'), as a kind of 'surface' anaphora (or ellipsis, in the revised terminology of Sag and Hankamer 1984), and

- a null proform $e_{N}$, a kind of 'deep' anaphora ("model-theoretic" anaphora, in the term of Sag and Hankamer 1984)

While uniform alternatives to this analysis are conceivable, they would require the otiose positing of distinctions among the values of gender features and fail to capture the full range of data.

\section{Predicate adjectives under ellipsis}

Greek predicate ellipsis comes in two varieties: either the material that usually follows a copular verb like ime 'be' is missing (this is similar to the 'VP' ellipsis of English, more neutrally called 'post-auxiliary ellipsis'; see Miller 2011) or a subject NP is 'stripped' out of a clause (in this paper, I will use both constructions when convenient). Greek has two numbers (singular, plural) and three genders (masculine, feminine, neuter). Nouns denoting inanimate objects and most animals may belong to any of the three gender classes, but nouns denoting humans (and some animals, though I will consider only humans here) display the gender that corresponds to the sex of the referent (with a handful of exceptions to be discussed below). Predicates agree in number, gender, and case with their subjects; adjectives are morphologically indistinguishable from nouns, showing the same set of distinctions that are found in the noun. Adjectives used attributively agree with the noun they modify; when used predicatively, adjectives agree with their subjects. 
When a predicate ellipsis has a predicate adjective as its antecedent, such ellipses are well-formed when the subject of the antecedent predicate and that of the elided predicate match in gender and number:

(2) a. O Petros ine ikanos, ala o Alexandros dhen ine. the Petros is capable.m.sg but the Alexander not is 'Petros is capable, but Alexander isn't.'

b. I Maria ine ikani, ala i Anna dhen ine. the Maria is capable.f.s but the Anna not is 'Maria is capable, but Anna isn't.'

c. To koritsi ine ikano, ala to agori dhen ine. the girl.neut.sg is capable.n.sg but the boy.neut.sg not is 'The girl is capable, but the boy isn't.'

d. I pateradhes ine ikani, ala i papudhes dhen ine. the fathers.m.pl are capable.m.pl but the grandfathers.m.pl not are 'The fathers are capable, but the grandfathers aren't.'

e. I miteres ine ikanes, ala $\mathrm{i}$ jajadhes dhen ine. the mothers.f.pl are capable.f.pl but the grandmothers.f.pl not are 'The mothers are capable, but the grandmothers aren't.'

f. Ta koritsia ine ikana, ala ta agoria dhen ine. the girls.n.pl are capable.n.pl but the boys.n.pl not are 'The girls are capable, but the boys aren't.'

But these are not the only possibilities for combination: with adjectival predicate ellipsis, any combination of gender and number between the antecedent and the elided predicate is possible:

$$
\left\{\begin{array}{ll}
\text { O Petros } & \text { ine ikanos } \\
\text { I Maria } & \text { ine ikani } \\
\text { To koritsi } & \text { ine ikano } \\
\text { I pateradhes } & \text { ine ikani } \\
\text { I miteres } & \text { ine ikanes } \\
\text { Ta koritsia } & \text { ine ikana } \\
\text { the } X_{\phi: \alpha} & \text { be capable } \\
\phi: \alpha
\end{array}\right\} \text { ala }\left\{\begin{array}{ll}
\text { o Alexandros } & \text { dhen ine } \\
\text { i Anna } & \text { dhen ine } \\
\text { to agori } & \text { dhen ine } \\
\text { i papudhes } & \text { dhen ine } \\
\text { i jajadhes } & \text { dhen ine } \\
\text { ta agoria } & \text { dhen ine } \\
\text { the } Y_{\phi: \beta} & \text { not be }
\end{array}\right\} \text {. }
$$

One might be tempted on the basis of such facts to posit the following generalization, and to formulate the identity condition on ellipsis accordingly: 


\section{(4) Gender and ellipsis generalization (incorrect version):} Gender and number are irrelevant to ellipsis. ${ }^{2}$

(5) $\mathrm{An}_{\mathrm{XP}}$ can be elided under identity with an antecedent $\mathrm{YP}_{A}$ just in case $\mathrm{XP}=\mathrm{YP}$ (or $\llbracket \mathrm{XP} \rrbracket=\llbracket \mathrm{YP} \rrbracket$ ) except for $\phi$-features ${ }^{3}$

While tempting, and adequate to the adjectival facts, the facts of ellipsis with nouns show that this generalization is far too sweeping, and we will need to distinguish between the gender features on adjectives and those on some nouns.

\section{Nouns under ellipsis}

A substantial literature on nominal ellipses ${ }^{4}$ has identified three classes of nouns in Romance that differ from each other in their behavior under ellipsis. ${ }^{5}$ The first class (exemplified by the Spanish pair tio/tía 'uncle/aunt') shows no alternations: that is, neither element of the pair can antecede a putative ellipsis of the other element of the pair. The second class—-such as abogado/abogada 'lawyer' allows alternations in either direction, when the nouns are used as predicates. The third class - actor/actriz 'actor/actress' —-shows a one-way alternation: the masculine element of the pair can antecede a putative ellipsis of a feminine, but the feminine cannot antecede a masculine (all examples from Depiante and Masullo 2001). ${ }^{6}$

\footnotetext{
${ }^{2}$ Presumably part of the well-known generalization that inflectional morphology is usually irrelevant to ellipsis. Number is irrelevant even in argument positions; see the appendix for data on number.

${ }^{3}$ Or, equally adequate for present purposes: A phrase marker $p$ which normally would have a daughter XP may lack that daughter and nonetheless be well-formed only if there is a YP accessible, where $\mathrm{YP}=\mathrm{XP}$ (or $\llbracket \mathrm{XP} \rrbracket=\llbracket \mathrm{YP} \rrbracket$ ) except for $\phi$-features.

${ }^{4}$ See, among others, Brucart 1987, 1999, Ritter 1988, Picallo 1991, Bernstein 1993, Kester 1996, Sleeman 1996, Giannakidou and Stavrou 1999, Depiante and Masullo 2001, Kornfeld and Saab 2002, Panagiotidis 2003a, 2003b, Masullo and Depiante 2004, Barbiers 2005, Nunes and Zocca 2005, 2010, Corver and van Koppen 2010, 2011, Alexiadou and Gengel 2012, Depiante and Hankamer 2008, Saab 2008, 2010, Zamparelli 2008, Bobaljik and Zocca 2010, Eguren 2010, Cornilescu and Nicolae 2012, Lipták and Saab 2011; and see Lobeck 2006 for an overview.

${ }^{5}$ For reasons of analytical focus and for space, I do not undertake a systematic comparison of the present approach with the wide variety of proposals in the literature, many of which contain insightful discussion of additional data concerning nominal modification, epithets, nominal argument structure, and the geometry of the nominal extended projection. See Saab 2008 for extensive discussion.

${ }^{6}$ In these examples, I reproduce Depiante and Masullo's stigmatic marks, e.g., '*’. As a reviewer points out, this mark should be taken as indicating some kind of unacceptability, though
} 
(6) a. * Juan es un buen tío y María también. Juan is a.m good.m uncle.m and Maria also

b. * María es una buena tía y Juan también. Maria is a.f good.f aunt.f and Juan also

(7) a. Juan es abogado y María también. Juan is lawyer.m and Maria also 'Juan is a lawyer, and Maria is, too.'

b. María es abogada y Juan también. Maria is lawyer.f and Juan also 'Maria ia a lawyer, and Juan too.'

(8) a. Juan es actor y María también. Juan is actor.m and Maria also

'Juan is an actor and Maria, too.'

b. ?? Maria es actriz y Juan también. Maria is actress.f and Juan also

These three classes can also be found in Greek, as shown in detail in the following three sections.

\subsection{Nonalternating nouns (adherfos/adherfi 'brother/sister')}

The first class consists of noun pairs like adherfos/adherfi 'sibling (male)/sibling (female)'. These do not alternate under ellipsis at all: neither when used as predicates, nor as arguments, as shown in (9) and (10). ${ }^{7}$

the source of that judgment is open to analysis. Rather than attempt to adjudicate between 'syntactic/morphological' ill-formedness marked by '*' and some kind of 'semantic/pragmatic' anomaly marked by '\#', I will keep to '*' and its brethren and ask the reader to keep this analytical caveat in mind.

${ }^{7}$ It is worth noting here that the judgments I report throughout this paper are true of a small sample of speakers for the items reported in the examples (five speakers for these items), as well as for one or two speakers for all the items in the lists (which, however, were not tested with all five speakers). Further, it is important to note that the judgments are relative, and hold within the pairs; no attempt at cross-pair comparison was made. Lastly, some speakers vary in which class they assign a given pair to; the examples consist of cases where speakers were uniform, but the lists contain items that are true of at least one speaker (while others may differ: for example, though thios/thia 'uncle/aunt' is listed here in the one-way alteranting class in accordance with the judgments of my primary informant, at least one speaker assigned it to the nonalternating class). A fuller exploration of the variation in this domain is needed. 


\title{
(9) As predicates:
}

\author{
a. * O Petros ine kalos adherfos, ala $\mathrm{i}$ Maria ine mia \\ the Petros is good.masc brother.masc but the Maria is a.fem \\ kakia. \\ bad.fem
}

(on the meaning 'Petros is a good brother, but Maria is a bad one (sister).' $)^{8}$

b. * I Maria ine kali adherfi, ala o Petros ine enas the Maria is good.fem sister.fem but the Petros is a.masc kakos.

bad.masc

(on the meaning 'Maria is a good sister, but Petros is a bad one (brother).')

(10) As arguments:

a. * O Petros exi enan adherfo stin Veria, ala dhen exi mia the Petros has a.masc brother in.the Veria but not has one.fem stin Katerini.

in.the Katerini

('Petros has a brother in Veria, but he doesn't have one (sister) in Katerini.')

b. * O Petros exi mia adherfi stin Veria, ala dhen exi enan the Petros has a.fem sister in.the Veria but not has one.masc stin Katerini.

in.the Katerini

('Petros has a sister in Veria, but he doesn't have one (brother) in Katerini.')

When gender matches, such structures are acceptable. In the following examples, I use, varyingly, adjectival and PP modifiers to supply contrastive elements (see Eguren 2010 and Cornilescu and Nicolae 2012 on this requirement). In each case, the point is the same: these elements do not differ in their distribution with elided and nonelided nominal phrases. Adjectives show agreement, while PPs avoid a possible confound with nominalized adjective uses; see Giannakidou and Stavrou 1999 for tests to distinguish nominal ellipsis from such adjectives in

\footnotetext{
${ }^{8}$ This example is acceptable where it is taken not to involve nominal ellipsis at all: instead, the adjective can be interpreted as a nominalization, in which case the meaning is 'Maria is a bad person'. Informants reject this sentence only on the intended reading where we understand Maria to be a bad sister, and that is the judgment reported with the stigmatic mark ' $*$ '.
} 
Greek. The distribution of the indefinite article is fairly complex in Greek, and in general is dispreferred with predicates, being more acceptable when the head noun is missing; this fact results in a slight degradation, not indicated here, in all predicate uses of indefinite articles-I retain the article, however, as dropping it would lead to an overwhelming preference for the parse of the adjective as being a plain predicative adjective, not an attributive modifying a missing nominal predicate.

a. O Petros ine kalos adherfos, ala o Kostas ine enas the Petros is good.masc brothermasc but the Kostas is a.masc kakos.

bad.masc

'Petros is a good brother, but Kostas is a bad one (brother).'

b. I Maria ine kali adherfi, ala i Anna ine mia kakia. the Maria is good.fem sisterfem but the Anna is a.fem bad.fem 'Maria is a good sister, but Anna is a bad one (sister).'

(12) a. O Petros exi enan adherfo stin Veria, ala dhen exi enan the Petros has a.masc brother in.the Veria but not has one.masc stin Katerini.

in.the Katerini

'Petros has a brother in Veria, but he doesn't have one (brother) in Katerini.'

b. O Petros exi mia adherfi stin Veria, ala dhen exi mia stin the Petros has a.fem sister in.the Veria but not has one.fem in.the Katerini.

\section{Katerini}

'Petros has a sister in Veria, but he doesn't have one (sister) in Katerini.'

a. O Petros exi enan kalo adherfo, ala dhen exi enan the Petros has a.masc good.masc brother but not has one.masc kako. bad.masc

'Petros has a good brother but he doesn't have a bad one (brother).'

b. O Petros exi mia kali adherf, ala dhen exi mia kakia. the Petros has a.fem good.fem sister but not has one.fem bad.fem 'Petros has a good sister, but he doesn't have a bad one (sister).' 
Here and throughout, I use a nominal subdeletion (' $\mathrm{N}^{\prime}$ '-ellipsis) construction, but the results are the same with canonical post-copular predicate ellipsis (after ime 'be') and with predicate stripping, both positive and negative (also known as bare argument ellipsis), illustrated in the following examples (see however Saab 2010 for an importantly different perspective on subnominal and predicate nominal ellipses). This holds for these ellipsis types both when used as predicates, as in (14)-(16), and as arguments, as in (17)-(18).

(14) Post-copular predicate ellipsis:

a. * $\mathrm{O}$ Petros ine adherfos, ala i Maria dhen ine. the.m Petros is brother.m but the.f Maria not is

('Petros is a brother, but Maria isn't.')

b. * I Maria ine adheri, ala o Petros dhen ine. the.f Maria is sister.m but the.m Petros not is

('Maria is a sister, but Petros isn't.')

(15) Positive stripping, predicate:

a. * O Petros ine adherfos, ke i Maria episis. the.m Petros is brother.m and the.f Maria too

('Petros is a brother, and Maria, too.')

b. * I Maria ine adherfi, ke i Petros episis. the.f Maria is sister.f and the.m Petros too

('Maria is a sister, and Petros, too.')

(16) Negative stripping, predicate:

a. * O Petros ine adherfos, ala i Maria oxi. the.m Petros is brother.m but the.f Maria not

('Petros is a brother, but not Maria.')

b. * I Maria ine adherfi, ala o Petros oxi. the.f Maria is sister.f but the.m Petros not

('Maria is a sister, but not Petros.')

(17) Positive stripping, argument

a. * O Petros exi enan adherfo stin Veria, ke mia stin Katerini the Petros has a.m brother.m in.the Veria and a.f in.the Katerini episis.

also

('Petros has a brother in Veria, and one (sister) in Katerini, too.') 
b. * O Petros exi mia adherfi stin Veria, ke enan stin Katerini the Petros has a.f sister in.the Veria and a.m in.the Katerini episis.

also

('Petros has a sister in Veria, and one (brother) in Katerini, too.')

Negative stripping, argument

a. * O Petros exi enan adherfo stin Veria, ala oxi mia stin the Petros has a.m brother.m in.the Veria but not a.f in.the

Katerini.

\section{Katerini}

('Petros has a brother in Veria, but not one (sister) in Katerini.')

b. * O Petros exi mia adherfi stin Veria, ala oxi enan stin Katerini. the Petros has a.f sister in.the Veria but not a.m in.the Katerini

('Petros has a sister in Veria, but not one (brother) in Katerini.')

The difficulty in (10), (17)-(18) comes from the gender mismatch, not from a some more general condition on nominal ellipses in argument position. In all the argument cases considered in this paper, NP-ellipsis is licit if the gender features match (and number need not match even in argument positions; see the appendix for the data, and see Giannakidou and Stavrou 1999, Panagiotidis 2002 for more discussion of nominal ellipses in Greek in particular). I have given illustrative examples are given here for this pair above; the same holds for the other noun classes to be discussed below. ${ }^{9}$

A fuller list of noun pairs that behave similarly is given in (19); it should be noted that all the morphologically related pairs denote either kinship terms or terms of nobility.

\footnotetext{
${ }^{9}$ Case is also irrelevant to the generalization. For this paper, I have chosen examples that are easy for informants to judge, in which the predicate nominals appear in the nominative (agreeing with finite subjects) and in which the argument nominals appear in the accusative (as direct objects of the verb exo 'have'). This alternation is seen morphologically only on masculines, where the nominal endings differ: $-o s$ is nominative, $-o$ is accusative. But predicate nominals may appear in the accusative (when they agree with small clause subjects which themselves are accusative, as objects of verbs like theoro 'consider', etc., and naturally arguments may be in the nominative, when appearing as subjects:

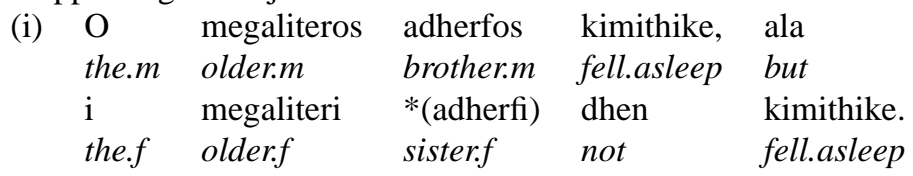


(19) Noun pairs that do not alternate at all (neither as predicates nor as arguments)

\begin{tabular}{llll} 
masculine & \multicolumn{3}{c}{ feminine } \\
\hline adherfos & 'brother' & adherfi & 'sister' \\
kirios & 'mister/gentleman' & kiria & 'ma'am/woman' \\
ksadherfos & '(male) cousin' & ksadherfi & '(female) cousin' \\
engonos & 'grandson' & engoni & 'granddaughter' \\
vaftistikos & 'godson' & vaftistikia & 'goddaughter' \\
antras & 'man, husband' & jineka & 'woman, wife' \\
pateras & 'father' & mitera & 'mother' \\
babas & 'dad' & mama & 'mom' \\
jos & 'son' & kori & 'daughter' \\
papus & 'grandfather' & jaja & 'grandmother' \\
gambros & 'groom, son-in-law' & nifi & 'bride, daughter-in-law' \\
prinkipas & 'prince' & prinkipissa & 'princess' \\
vasilias & 'king' & vasilissa & 'queen' \\
aftokratiras & 'emperor' & aftokratira & 'empress'
\end{tabular}

\subsection{Two-way alternating nouns (jatros 'doctor $(\mathrm{m} / \mathbf{f})$ ')}

Epicene (or 'hybrid' or 'variable gender'; see Corbett 1991 and Aikhenvald 2000) nouns have only one form, but their concord and agreement patterns are determined by the natural (or 'semantic') gender of their referent (seen in the article, attributive adjectives, predicate adjectives, relative pronouns, and other anaphoric pronouns):
a. I kali jatros itan xarumeni. Tin agapusame. the.fem good.fem doctor was happy.fem her loved.3p 'The good doctor (female) was happy. We loved her.'
b. $\mathrm{O}$ kalos jatros itan xarumenos. Ton agapusame. the.masc good.masc doctor was happy.masc him loved.3p 'The good doctor (male) was happy. We loved him.'

Note that this isn't just 'natural' or 'semantic' agreement (agreement ad sensum) overriding grammatical/syntactic agreement (agreement ad formam), as is possible with certain neuter nouns denoting animates (koritsi 'girl', agori 'boy', pedhi 'child', melos 'member') and anaphoric pronouns: ${ }^{10}$

\footnotetext{
${ }^{10}$ These nouns in Greek are thus different from better known cases of 'hybrid' agreement as in (i), from Corbett 1991, discussed in Wechsler and Zlatić 2003 and Villavicencio et al. 2005
} 
(21) a. To kalo koristi itan xarumeno. $\{$ To/tin $\}$ agapusame. the.neut good.neut girl.neut was happy.neut it/her loved.3p 'The good girl was happy. We loved it/her.'

b. i. * I koristi itan eki. the.fem girl.neut was there

ii. * Kales koritsia itan eki. good.fem girls.neut were there

iii. * To koritsi itan xarumeni. the.neut girl.neut was happy.fem

In other words, we accept the traditional analysis of these nouns as being listed twice in the lexicon, once with a masculine gender and once with a feminine (they are homophones, but not vague). Despite having different lexically determined gender features, however, they participate in elliptical relations in both directions: a masculine noun can serve as the antecedent to a putative feminine form, and vice versa, as shown in (22).

\section{(22) As predicates:}

a. O Petros ine kalos jatros, ala i Maria ine mia kakia. the Petros is good.masc doctor but the Maria is a.fem bad.fem 'Petros is a good doctor, but Maria is a bad one.'

b. I Maria ine kali jatros, ala o Petros ine enas kakos. the Maria is good.fem doctor but the Petros is a.masc bad.masc 'Maria is a good doctor, but Petros is a bad one.'

Despite this and their phonological surface identity, these pairs of nouns do not easily license ellipsis of their opposite-gendered counterparts when used in argument position:

(23) As arguments:

a. * O Petros exi enan jatro stin Veria, ala dhen exi mia the Petros has a.masc doctor in.the Veria but not has one.fem

stin Katerini.

in.the Katerini

(cf. also Collins and Postal 2011 on 'imposters'):

(i) $\mathrm{Su}$ Majestad Suprema está contento. (Él ...)

Poss.3 Majesty.fem Supreme.fem is happy.masc (He.masc ...)

'His Supreme Majesty is happy. (He ...)' 
('Petros has a (male) doctor in Veria, but he doesn't have one (female doctor) in Katerini.')

b. * O Petros exi mia jatro stin Veria, ala dhen exi enan the Petros has a.fem doctor in.the Veria but not has one.masc

stin Katerini.

in.the Katerini

('Petros has a (female) doctor in Veria, but he doesn't have one (male doctor) in Katerini.')

A partial list of such epicene nouns is given below; this is a productive class, and includes many professions, as well as some kinship and other terms.

(24) Epicene nouns alternate under ellipsis in either direction as predicates (but in neither direction as arguments)

antipalos 'opponent', apostoleas 'sender', asthenis 'patient/sick person', astinomikos 'police officer', dhiermineas 'interpreter', dhikastis 'judge', dhikigoros 'lawyer', dhimosiografos 'journalist', epangelmatias 'professional', epistimonas 'scientist', filologos 'philologist', fisikos 'physicist', glossologos 'linguist', goneas 'parent' gramateas 'secretary', idhravlikos 'plumber', iereas 'priest/pastor', ithopios 'actor', ipalilos 'employee', ipurgos 'minister', istorikos 'historian', jatros 'doctor', jeografos 'geographer', jeoponos 'agrologist', kalitexnis 'artist', kinigos 'hunter', listis 'thief', marangos 'carpenter', martiras 'witness', mastoras 'handyperson', mathematikos 'mathematician', mixanikos 'engineer, mechanic', musikos 'musician', odhigos 'driver', pedhagogos 'pedagogue', pilotos 'pilot', politis 'citizen', proedhros 'president, chairperson', prothipurgos 'prime minister', sinergatis 'collaborator', singenis 'relative', singrafeas 'writer', sizigos 'spouse', tamias 'cashier', ximikos 'chemist', zografos 'artist, painter'

The following pair of sentences exemplifies the contrast between predicate and argument use in as close to a minimal pair as it is possible to construct:

(25) Predicate vs. argument use, minimal pairs:

a. O Petros ine enas jatros stin K., ke i Maria ine mia stin Athina. the Petros is a.masc doctor in.the K. and the Maria is one.fem in.the Athens

b. * $\mathrm{O}$ Petros exi enan jatro stin K., ke i Maria exi mia stin Athina. has has

'Petros $\{$ is/has $\}$ a (male) doctor in Katerini, and Maria $\{$ is/*has $\}$ one (female doctor) in Athens.' 


\subsection{One-way alternating nouns (dhaskalos/dhaskala 'teacher')}

The third and final class of nouns consists of pairs like dhaskalos/dhaskala 'teacher', in which the masculine form can antecede an elided feminine when both are predicates, but not vice versa; we could call them, adopting the Greek for 'one-way street', monodromic. When in argument position, these nouns, like the previous two classes, fail to allow ellipsis in either direction.

(26) As predicates:

a. O Petros ine kalos dhaskalos, ala i Maria ine mia the Petros is good.masc teacher.masc but the Maria is a.fem kakia.

bad.fem

'Petros is a good teacher, but Maria is a bad one.'

b. * I Maria ine kali dhaskala, ala o Petros ine enas the Maria is good.fem teacher.fem but the Petros is a.masc kakos.

bad.masc

'Maria is a good teacher, but Petros is a bad one.'

(27) As arguments:

a. * O Petros exi enan dhaskalo stin Veria, ala dhen exi mia the Petros has a.masc teacher.m in.the Veria but not has one.fem stin Katerini.

in.the Katerini

('Petros has a (male) teacher in Veria, but he doesn't have one (female teacher) in Katerini.')

b. * O Petros exi mia dhaskala stin Veria, ala dhen exi enan the Petros has a.fem teacher in.the Veria but not has one.masc

stin Katerini.

in.the Katerini

('Petros has a (female) teacher in Veria, but he doesn't have one (male teacher) in Katerini.')

(28) Noun pairs in which the masculine form can antecede ellipsis in a predicate of the feminine, but not vice versa (and in neither direction in argument position) 


\begin{tabular}{|c|c|c|c|c|c|}
\hline masculine & feminine & & & & \\
\hline dhaskalos & dhaskala & 'teacher' & kathijitis & kathijitria & 'professor' \\
\hline mathitis & mathitria & 'pupil' & fititis & fititria & 'student' \\
\hline pianistas & pianistria & 'pianist' & athlitis & athlitria & 'athlete' \\
\hline tragudhistis & tragudhistria & 'singer' & furnaris & furnarissa & 'baker' \\
\hline theos & thea & 'god' & sxoliastis & sxoliastria & 'commentator' \\
\hline nosokomos & nosokoma & 'nurse' & ipiretis & ipiretria & 'servant' \\
\hline katharistis & katharistria & 'cleaner' & pirosvestis & pirosvestria & 'firefighter' \\
\hline papas & papissa & 'pope' & manavis & manavissa & 'greengrocer' \\
\hline stratiotis & stratiotina & 'soldier' & piitis & piitria & 'poet' \\
\hline latris & latrissa & ‘worshiper' & filos & fili & 'friend' \\
\hline kumbaros & kumbara & $\begin{array}{l}\text { 'best man'/ 'maid } \\
\text { of honor' }\end{array}$ & nonos & nona & $\begin{array}{l}\text { 'godfather'/ } \\
\text { 'godmother' }\end{array}$ \\
\hline thios & thia & 'uncle'/'aunt' & thavmastis & thavmastria & 'admirer' \\
\hline
\end{tabular}

By two other tests for gender markedness (the plural test and the existential pivot test; see Corbett 1991, and Bobaljik and Zocca 2010 in particular), masculine is unmarked in these pairs, as it is in the other pairs as well:

(29) a. i dhaskales $[$ fem $]=$ a group of female teachers only

b. $\quad$ i dhaskali $i_{\text {masc }]}=$ a group of male teachers, or a mixed group

a. Exi enan dhaskalo stin fotografia? Ne, tin Maria. have a.m teacher.masc in.the picture yes the Maria 'Is there a teacher in the picture? Yes, there is Maria.'

b. Exi mia dhaskala stin fotografia? \#Ne, ton Petro. have a.f teacherfem in.the picture yes the Petros 'Is there a teacher in the picture? \#Yes, there is Petros.'

\subsection{Summary}

The following table summarizes the patterns seen in the data so far: 


\begin{tabular}{cc|c|c}
\hline \multicolumn{4}{c}{ Can $N$ vary under ellipsis as (part of) a(n)... } \\
\hline & ...predicate? & ...argument? & examples of $N$ \\
\hline a. & No & No & \\
& $m \leftrightarrow f$ & $m \leftrightarrow f$ & adherfos/adherfi 'brother/sister' \\
\hline b. & Yes & No & \\
& $m \leftrightarrow f$ & $m \leftrightarrow f$ & jatros/jatros 'doctor' \\
\hline c. & One way only: & No & \\
& $m_{A} \rightarrow f_{E}$ & $m \leftrightarrow f$ & dhaskalos/dhaskala 'teacher' \\
\hline
\end{tabular}

This table is not accidentally similar to tables that have summarized related data in the previous literature, such as the following table from Bobaljik and Zocca 2010:

(32) (Table from Bobaljik and Zocca 2010)

\begin{tabular}{c|c|c} 
Class of predicative nouns & $\begin{array}{c}\text { masc antecedent } \\
\text { fem ellipsis }\end{array}$ & $\begin{array}{c}\text { fem antecedent } \\
\text { masc ellipsis }\end{array}$ \\
\hline prince/princess (invariant) nouns & $*$ & $*$ \\
\hline doctor/doctor $(\mathrm{m} \leftrightarrow \mathrm{f})$ nouns & $\checkmark$ & $\checkmark / ?$ \\
\hline actor/actress $(\mathrm{m} \rightarrow \mathrm{f}$ ) nouns & $\checkmark$ & $*$
\end{tabular}

The main difference between the table in (31) and such earlier tables is that the present table considers also the behavior of these noun pairs in argument positions. This difference is crucial to understanding the full implications of these data for the theory of ellipsis licensing.

Crucially, at least the morphologically related pairs $d o$ alternate in deaccented contexts, although their status is comparable to that of voice mismatches in English connective texts (see Merchant 2013c for some discussion).

(33) Nonalternating noun pairs, deaccented:

a. O Petros ine kalos adherfos, ala i Maria ine mia the Petros is good.masc brother.masc but the Maria is a.fem kakia adherfi. bad.fem sister.f 'Petros is a good brother, but Maria is a bad sister.'

b. I Maria ine kali adherfi, ala o Petros ine enas the Maria is good.fem sisterfem but the Petros is a.masc kakos adherfos.

bad.masc.

'Maria is a good sister, but Petros is a bad brother.' 
c. O Petros exi enan adherfo stin Veria, ala dhen exi mia the Petros has a.masc brother in.the Veria but not has one.fem adherfi stin Katerini. sisterf in.the Katerini 'Petros has a brother in Veria, but he doesn't have a sister in Katerini.'

d. O Petros exi mia adherfi stin Veria, ala dhen exi enan the Petros has a.fem sister in.the Veria but not has one.masc aderfo stin Katerini. brother.m in.the Katerini

'Petros has a sister in Veria, but he doesn't have a brother in Katerini.'

(34) Epicene noun pairs, deaccented:

a. O Petros ine kalos jatros, ala i Maria ine mia kakia the Petros is good.masc doctor but the Maria is a.fem bad.fem jatros.

doctor.f

'Petros is a good doctor, but Maria is a bad doctor.'

b. I Maria ine kali jatros, ala o Petros ine enas kakos the Maria is good.fem doctor but the Petros is a.masc bad.masc jatros. doctor.m

'Maria is a good doctor, but Petros is a bad doctor.'

c. O Petros exi enan jatro stin Veria, ala dhen exi mia the Petros has a.masc doctor in.the Veria but not has one.fem jatro stin Katerini. doctor. in.the Katerini 'Petros has a (male) doctor in Veria, but he doesn't have a (female) doctor in Katerini.'

d. O Petros exi mia jatro stin Veria, ala dhen exi enan the Petros has a.fem doctor in.the Veria but not has one.masc jatro stin Katerini. doctor.m in.the Katerini 'Petros has a (female) doctor in Veria, but he doesn't have a (male) doctor in Katerini.'

(35) One way noun pairs, deaccented: 
a. O Petros ine kalos dhaskalos, ala i Maria ine mia the Petros is good.masc teacher.masc but the Maria is a.fem kakia dhaskala. bad.fem teacher.f 'Petros is a good teacher, but Maria is a bad teacher.'

b. I Maria ine kali dhaskala, ala o Petros ine enas the Maria is good.fem teacherfem but the Petros is a.masc kakos dhaskalos. bad.masc teacher.m 'Maria is a good teacher, but Petros is a bad teacher.'

c. O Petros exi enan dhaskalo stin Veria, ala dhen exi mia the Petros has a.masc teacher.m in.the Veria but not has one.fem dhaskala stin Katerini. teacher in.the Katerini 'Petros has a (male) teacher in Veria, but he doesn't have a (female) teacher in Katerini.'

d. O Petros exi mia dhaskala stin Veria, ala dhen exi enan the Petros has a.fem teacher in.the Veria but not has one.masc dhaskalo stin Katerini.

teacher. $m$ in.the Katerini

'Petros has a (female) teacher in Veria, but he doesn't have a (male) teacher in Katerini.'

We are led to conclude that the patterns found under ellipsis must be attributed to the way the ellipsis is resolved, and do not fall out from more general mechanisms regulating the nature of contrastive focus in connected discourse.

\section{$3 \quad$ PF-deletion and null proforms}

There have been a wide variety of proposals made for dealing with the facts of ellipsis, concerning both the local licensing conditions (are particular heads or structures involved in ellipsis?) and potentially nonlocal 'identification' conditions (what is the nature of the relation between the missing material and its notional antecedent?); see Merchant 2009 and van Craenenbroeck and Merchant 2013 for recent surveys. In the remainder of this paper, I explore the implications of these facts for our understanding of the mechanisms of elliptical resolution, demonstrating that a heterogeneous approach to elliptical phenomena (going back 
to Hankamer and Sag 1976 and modified in Sag and Hankamer 1984 and van Craenenbroeck 2010) can capture the attested patterns.

\subsection{A semantic theory of gender on human-denoting nouns}

Cooper 1983 proposed that gender features on animate pronouns are presuppositions, which can be implemented using partial identity functions over the type of individuals, as Heim and Kratzer 1998 do.

$$
\begin{aligned}
& \llbracket \text { masculine } \rrbracket=\lambda x_{e}: x \text { is male }[x] \\
& \llbracket f \text { eminine } \rrbracket=\lambda x_{e}: x \text { is female }[x]
\end{aligned}
$$

Heim 2008 considers an articulated syntax for pronouns to accommodate person, number, and gender features:

(37) If $\beta$ is a pronoun and $i$ an index, then for any assignment $g$, $\llbracket \beta_{i} \rrbracket^{g}=g(i)$ (or undefined, if $i$ is not in the domain of $g$ ):

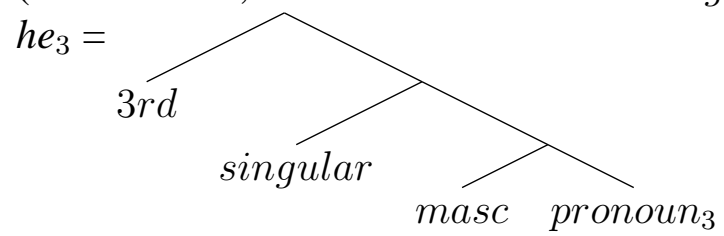

If the extended projection of the noun (see Alexiadou et al. 2007 for extensive references and discussion) contains a node encoding Gender, then an extension of Cooper's approach to human-denoting noun meanings is straightforward (compare Dowty and Jacobson 1989 for an attempt to do something similar for all nouns, for grammatical gender ${ }^{11}$ ).

I propose that the gender feature on the Gender node that combines with human-denoting nouns in Greek has one of two values: masculine or feminine. These features denote the partial functions given in (39). ${ }^{12}$

\footnotetext{
${ }^{11}$ See also Collins and Postal 2011 for recent discussion (and Tasmowski-De Ryk and Verluyten 1981, 1982 for earlier relevant observations)

${ }^{12}$ It is obvious that human semantic gender, under consideration here, and syntactic gender interact; we should assume that the syntax represented by (38) is uniform, though a full theory of how the syntactic features masculine and feminine behave when they are not interpreted by rules such as those in (39) is the topic of a much larger investigation; see Alsina and Arsenijevic 2012. The simplest hypothesis for a language like Greek is that that the denotations in (39) apply only
} 
(38)

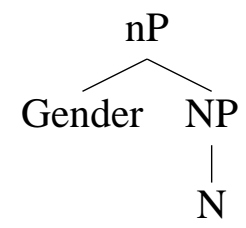

(39)

$$
\begin{aligned}
& \llbracket \text { masculine } \rrbracket=\lambda P_{e t} \lambda x_{e}: x \text { is male }[P(x)] \\
& \llbracket \text { feminine } \rrbracket=\lambda P_{e t} \lambda x_{e}: x \text { is female }[P(x)]
\end{aligned}
$$

Since the syntax of the NP is uniform across the human noun classes (and presumably beyond) and since the gender features receive the same meanings, the analysis thus far cannot distinguish among the three classes that have been identified. In order to accomplish that, I propose that the lexical meanings of the various nouns in these classes vary among themselves in whether or not the gender information is also encoded. The proposal is that certain nouns (those that do not license alternations: adherfos, adherfi, dhaskala) are lexically specified for the sex of the entities that they denote, while the other class (dhaskalos, jatros, jatros) is not. This information is redundant in the system, as it is also provided as the semantic contribution of the Gender node with which these nouns combine; we may interpret this redundancy as a kind of strength of association of the meaning to the lexeme, if we wish, though this implementation does not capture a gradient sense. ${ }^{13}$ I thus assign the following representations to each of the noun types:
a. 【adherfos $\rrbracket=\lambda x_{e}: x$ is male $[\operatorname{sibling}(x)]$
b. $\llbracket$ adherfi $\rrbracket=\lambda x_{e}: x$ is female $[\operatorname{sibling}(x)]$
a. 【dhaskalos $\rrbracket=\lambda x_{e}[$ teacher $(x)]$
b. 【dhaskala $\rrbracket=\lambda x_{e}: x$ is female $[\operatorname{teacher}(x)]$

if $P$ is a set of humans, and that $\llbracket$ masculine $\rrbracket=\llbracket$ feminine $\rrbracket=\lambda P[P]$ otherwise. One way to combine this set of partially contingent presuppositions into a single lexical entry for the gender features the following.

(i) $\llbracket$ masculine $\rrbracket=\lambda P_{e t} \lambda x_{e}\left\{\begin{array}{l}\text { if }\{x \mid P(x)\} \subset\{x \mid \operatorname{human}(x)\} \text {, then }\left\{\begin{array}{l}\text { if } x \text { is male, } P(x) \\ \text { else, undefined }\end{array}\right\} \\ \text { else, } P(x)\end{array}\right\}$

\footnotetext{
${ }^{13}$ In fact, it may be useful to think of these features as being gradient, and contributing to the inter- and intra-speaker variation found in the acceptability of different pairs, even within the same class.
} 
The resulting structures will be uniform across all noun classes, and compose regularly: ${ }^{14}$
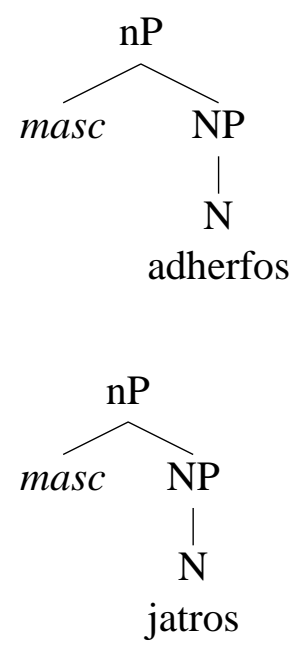
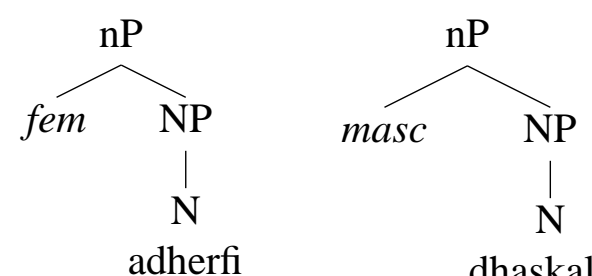

dhaskalos

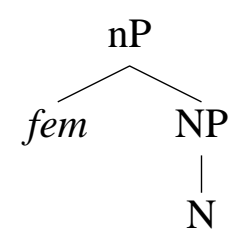

dhaskala

The proposal, then, is that these nouns differ semantically, but not syntactically.

\subsection{Two sources for silence in the Greek NP}

I propose that the grammar of Greek has at its disposal two strategies for generating nominal-internal ellipses: PF-deletion of GenderP (the $\mathrm{nP}$ headed by the nominal Gender feature or the $n$ head with Gender, on some accounts; the difference is

\footnotetext{
${ }^{14}$ This treatment thus differs from some earlier proposals, such as that of Chomsky 1965:179, that attempted to draw a distinction between features that required identity in ellipsis and those that did not by calling the former 'inherent' and the latter 'added ... by agreement transformations'. That some distinction must be drawn was first noted by de Vaugelas 1647, for certain adjectives in French:
}

Vaugelas (1647, pp. 461-462) maintains that such a facon de parler cannot be considered either "absolument mauvaise" or "fort bonne," and suggests that it be avoided when masculine and feminine forms of the Adjective differ. Thus, a man speaking to a woman should not say je suis plus beau que vous, but should rather ("pour parler regulièrement") resort to the paraphrase je suis plus beau que vous n'êtes belle, although it would be perfectly all right for him to say je suis plus riche que vous. (Chomsky 1965:233f. fn. 35)

It need hardly be added that French riche is an adjective that shows no gender distinctions. 
immaterial here), following Saab 2008, and a null pro-noun $e_{N}$, following Panagiotidis 2002. In the next subsections, I lay out the evidence for this dichotomy before turning to complete derivations of all of the data so far considered.

\subsubsection{PF-deletion}

Theories that assign a complete syntactic structure internal to the ellipsis site do so for a number of reasons (see Johnson 2001, Merchant 2013a, and van Craenenbroeck and Merchant 2013 for some recent overviews and comparisons to other approaches). Chief among these reasons is the ability of the ellipsis site to host the gap of an unbounded dependency and to control agreement on targets outside the ellipsis site. Both of these phenomena are found in Greek nominal ellipses. In (44a), we have extraction out of the ellipsis site (the genitive argument tis glossologias, as well as agreement out of the ellipsis site (the gender features on the determiner ton and adjective kenurio). These properties are consistent only with a structure such as that given in (44b), where the solid line indicates movement of the complement of the noun to its surface position, and the dotted lines indicate the agreement relation between the controller of agreement, the Gender feature in $\mathrm{nP}$, and the targets of agreement, the determiner and adjective.

(44) Tis istorias idha ton palio [proedhro __, kai ... the history.gen I.saw the.m old.m chair.m and 'I saw the former chairperson(masc) of the history department, and...'
a. ... tis glossologias tha dho ton kenurio. the linguistics.gen fut I.see the.m new.m (lit.) 'of linguistics, I'll see the new(masc) (one).' 
b. [tis glossologias $]_{3}$ tha dho DP

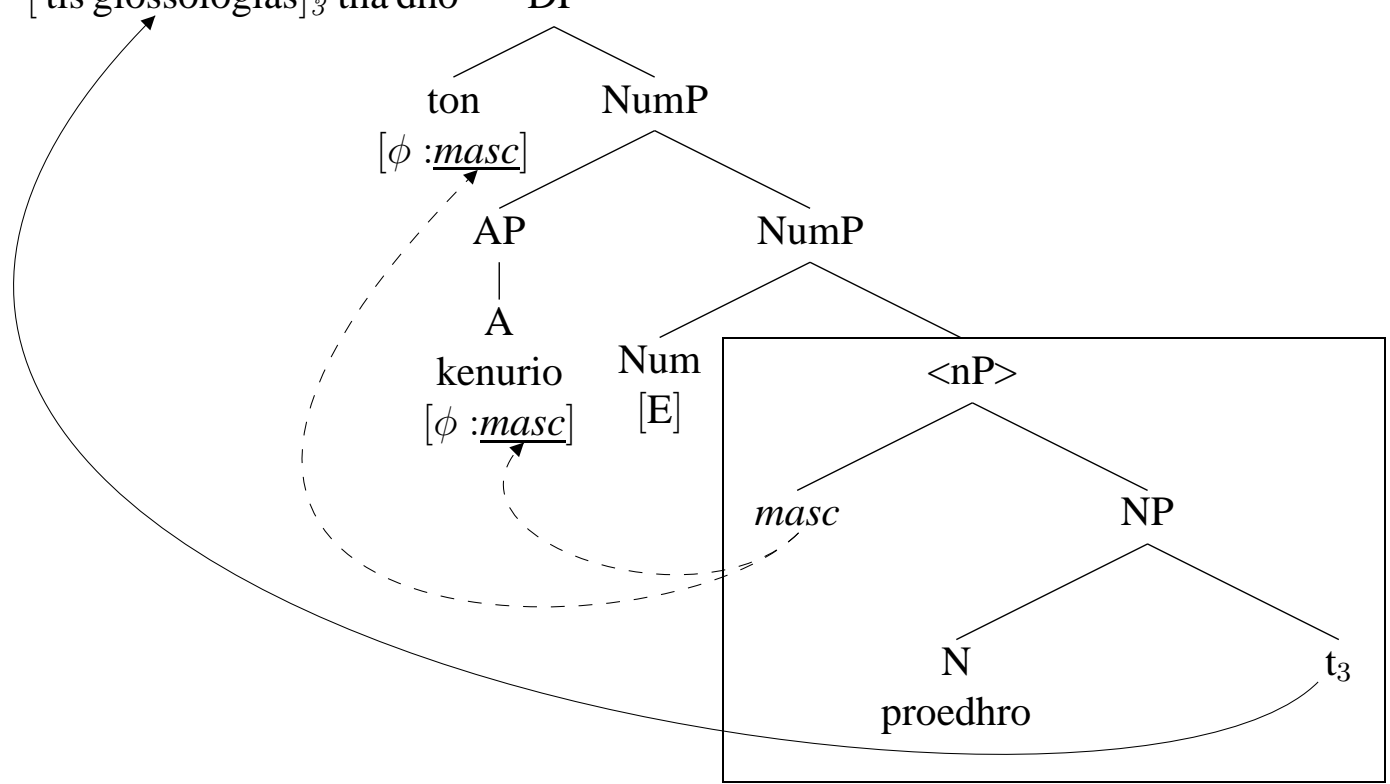

Variable gender elements such as the determiner and the adjective enter the derivation without $\phi$-feature specifications (e.g., $D:[\phi:-]$ ) and acquire them under Agree with masc (see Baker 2008, Kratzer 2009); this is consistent with the architectural assumption that Agree happens on a branch of the derivation that does not feed LF (if the resulting features would have to be interpreted; see Bobaljik 2008) or with the assumption that such inflectional features have no semantic effect at all.

The [E](llipsis) feature (here in its nominal variant, $\mathrm{E}_{n}$ ) appears here on Num: E is compatible with Num, but not Gender. This structural claim about DP-internal ellipsis is from Saab 2008, though my implementation differs. This is part of the local morphosyntactic 'licensing' requirement, encoding in the featural requirements of the E variant what kind of heads it can combine with or must appear near to; see van Craenenbroeck and Lipták 2006, Aelbrecht 2010, Lee 2012 for more discussion of the attested cross-linguistic variation here.

For the purposes of this paper, we can take the E-feature to impose semantic identity between the meaning of the node it 'deletes' and that node's antecedent: $\llbracket \mathrm{XP}_{A} \rrbracket=\llbracket \mathrm{YP}_{E} \rrbracket$ (but see much recent work, e.g., Kobele 2012, Craenenbroeck 2012, Chung 2013, Merchant 2013c, for suggestions that syntactic identity or identity of derivation is needed.) 
This strategy will be available for all gender-matching ellipses. In (45a), the elided $\mathrm{nP}_{2}$ is the complement to the Num head hosting the E-feature. While that Num's value may vary (and does, here), the value of the Gender feature on the $\mathrm{n}$ head of the elided node does not. The semantic equivalence required by $\mathrm{E}$ is satisfied, as shown in (45c), since the elided $\mathrm{nP}_{2}$ and its antecedent $\mathrm{nP}_{1}$ (both boxed in (45b)), are semantically identical.

a. O Petros exi enan jatro. Dhen exi dhio (jatrus).

the Petros has one.m doctor.m not has.3s two doctors.m

'Petros has one (male) doctor. He doesn't have two (male doctors).'

b. Peter has
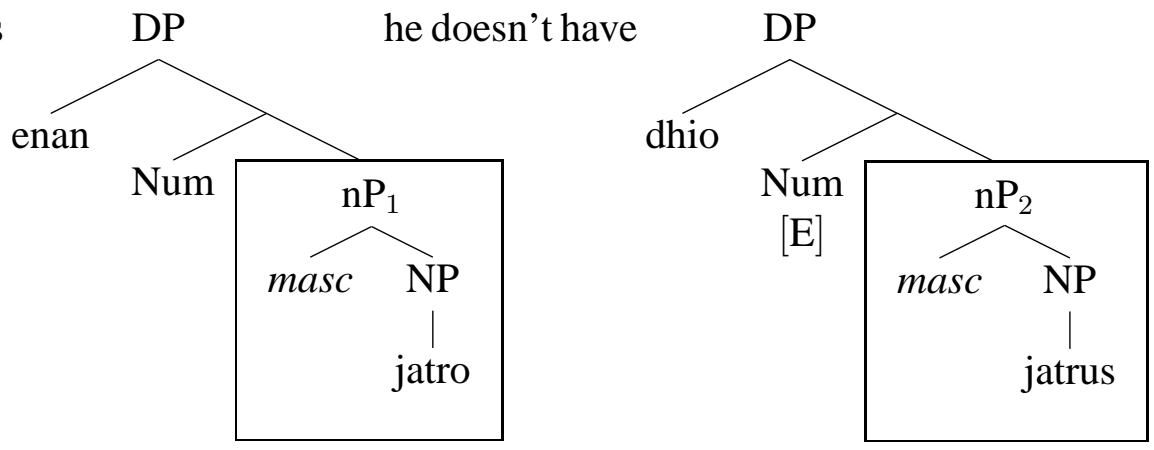

c. $\llbracket \mathrm{nP}_{1} \rrbracket=\llbracket \mathrm{nP}_{2} \rrbracket$

But the PF-deletion strategy regulated by the E-feature is not available for cases of gender-mismatches; in such cases, the [E] feature is too high in the structure: it imposes semantic identity on the nP nodes, as before, but now these nodes have contain conflicting semantic gender specifications.
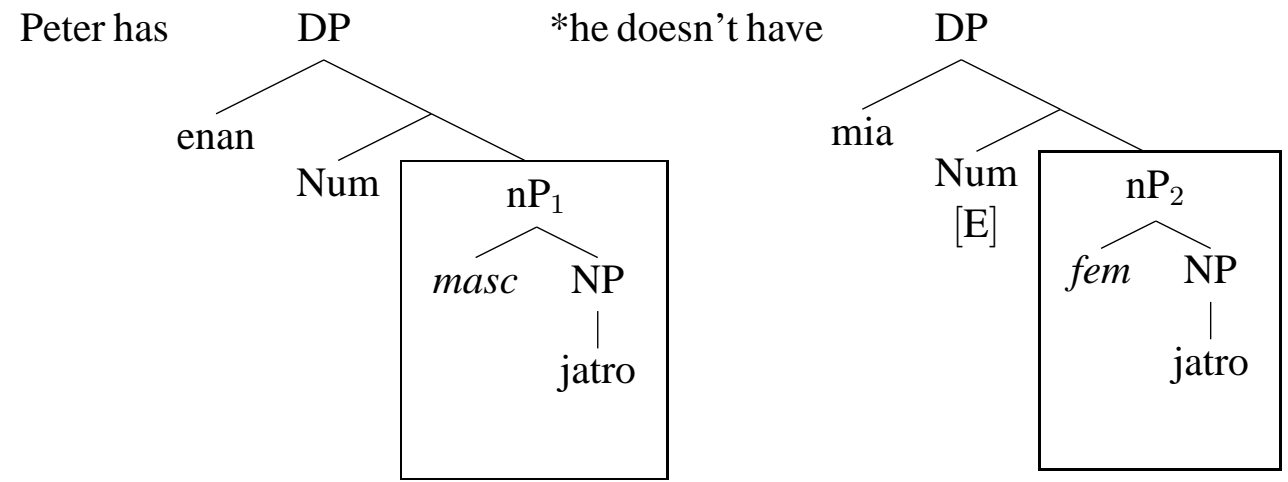

(47)

$$
\llbracket \mathrm{nP}_{1} \rrbracket \neq \llbracket \mathrm{nP}_{2} \rrbracket
$$


This correctly predicts that extraction out of gender mismatched NPs involving ellipsis will be degraded with respect to their gender matched counterparts. This is the case, as seen in the following example (compare the relative well-formedness of (44) above).

(48) Tis istorias idha ton palio [proedhro _ ], kai ... the history.gen I.saw the.m old.m chair.m and

...* tis glossologias tha dho tin kenuria. the linguistics.gen fut I.see the.f new.f

('(lit.) I saw the former chairperson(masc) of the history department, and of linguistics, I'll see the new(fem) (one).')

As is documented in the preceding section, however, there are many acceptable cases of gender mismatched ellipses that do not involve extraction. Since uniform PF-deletion of nP can't handle any such gender mismatched cases, a second mechanism is required.

\subsubsection{A null proform}

I propose that all gender mismatched cases involve a null proform, in particular a null noun, $e_{N}$, following Panagiotidis 2003a, 2003b for Greek. This null pro-noun has analogs in the English one and Afrikaans een/ene, as discussed in Barbiers 2005, Corver and van Koppen 2011, and others (though one may have more similarities with classifiers than the Greek item). My proposal is the following; like other anaphoric devices Greek $e_{N}$ is interpreted by reference to an assignment function that assigns values to free variables; the variable in this case is given by the index.

(49) $e_{N}$ must be indexed: it introduces a free variable over possibly complex nominal meanings whose value is given by the contextual assignment function:

$$
\llbracket e_{N i} \rrbracket^{g}=g(i)
$$

Typically, and particularly in all the cases of interest here, $e_{N}$ will need an antecedent; this requirement can be implemented with coindexing with an antecedent noun, though it need not be. In other words, free indices may matter- 
they can indicate antecedence relations among elements that may not (and typically do not) stand in a c-command relationship. ${ }^{15}$

The assignment function can be constrained by this indexing, including on antecedents. The anaphora in an English sentence such as (50a) with a simple noun antecedent can be resolved given indices on nouns and the rule of interpretation in (51).

(50) a. Bill bought an old ball ${ }_{2}$ and I bought a new one ${ }_{2}$.

b. $\llbracket$ one $_{2} \rrbracket^{g}=g(2)=\llbracket$ ball $_{2} \rrbracket^{g}$

(51) If $\beta$ is a noun and $i$ is an index, then for any assignment $g$ where $i$ is the domain of $g, \llbracket \beta_{i} \rrbracket^{g}=\llbracket \beta \rrbracket$ if $g(i)=\llbracket \beta \rrbracket$ (else it is undefined)

Naturally, the index on one need not correspond to an index on an antecedent, particularly (though not only) when the antecedent consists of a complex nominal expression, with modifiers or arguments. In such cases, the assignment function will need to assign to the value of the index on one a complex expression (of the semantic type of such nominal expressions, typically $\langle e, t\rangle$ in standard approaches ${ }^{16}$ ) formed by composing the antecedent phrase or by incorporating other information from the context. (Like other anaphoric devices, these may be used when the antecedent is partially or completely constructed from the context and lacks a linguistic expression.) Both English one and the Greek null $e_{N}$ can take both single nouns (with or without arguments) and multiword nominal expressions as antecedents. The difficult question of how the appropriate antecedent is determined in any given context is one for the pragmatics of anaphora resolution to resolve (see e.g. Günther 2012, Miller and Pullum 2013, and Payne et al. 2013).

The hypothesis for Greek then takes the following form:

(52) Hypothesis: Greek $e_{N}$ is a pro-noun selected for by Num (or is a pro-nP ${ }^{17}$ )

With these analytical elements in place, I turn to detailed exemplification of the patterns seen above.

\footnotetext{
${ }^{15}$ Naturally, we also need a theory of which kinds of variables need what kinds of antecedents: the old 'surface/deep' anaphora distinction is too coarse. We need something like Giannakidou's (2001) 'dependent' variables: a type-logical distinction within types that distinguishes variables that can be text-level existentially bound from those which require closer binders, etc.

${ }^{16}$ See Giannakidou and Rathert 2009 for a recent overview and Merchant 2010 for arguments that complex-typed variables must be used by the linguistic system.

${ }^{17}$ The variant in the parenthesis may be chosen depending on how one decides to encode such distributional restrictions; for example, Déchaine and Wiltschko 2010 claim that pronouns can pronominalize either DPs or $\phi$ Ps. For purposes of explicitness, I will code this by stipulating that Greek $e_{N}$ has the same value for its category feature as nP does.
} 


\subsection{Derivations of the three classes of nouns}

\subsubsection{One-way alternating nouns: feminine is presuppositional, masculine not}

I begin with the class exemplified by dhaskalos/dhaskala 'teacher', which allow a masculine to antecede an elided feminine, but not vice versa.

Consider first a potential PF-deletion analysis of a licit alternation in predicate position such as (53). The structure of the antecedent is given in (53b), with the antecedent $\mathrm{nP}_{1}$ boxed; the structure of the predicate containing the ellipsis is given in $(53 \mathrm{c})$, with the desired target of ellipsis, $\mathrm{nP}_{2}$, the complement to the Num head hosting the E-feature, also boxed.

(53) As predicates $(m \rightarrow f)$ :

a. O Petros ine kalos dhaskalos, ala i Maria ine mia the Petros is good.masc teacher.masc but the Maria is a.fem kakia.

bad.fem

'Petros is a good teacher, but Maria is a bad one.'

b. Peter is DP

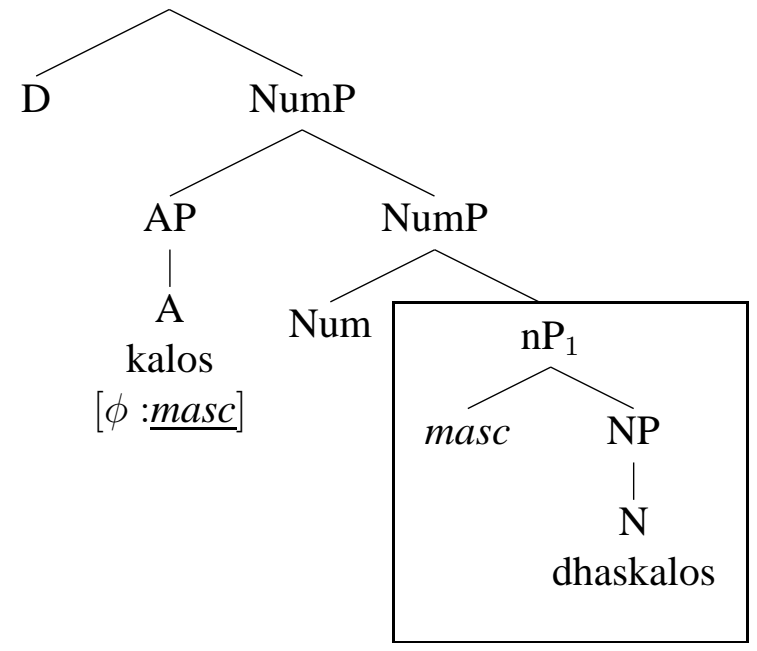




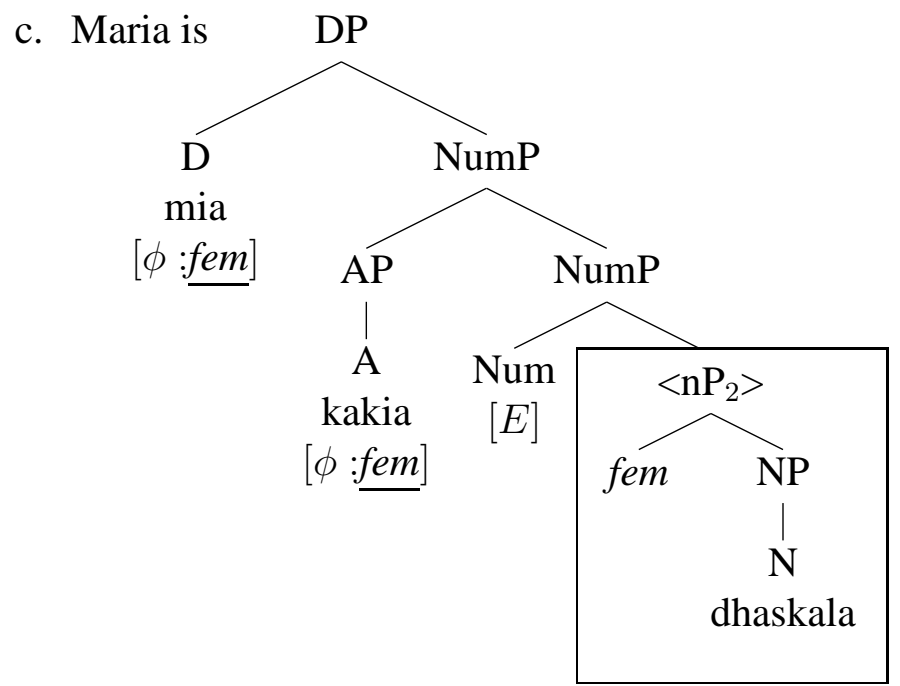

While these structures are an und für sich well-formed, PF-deletion cannot apply, because $\llbracket \mathrm{nP}_{1} \rrbracket \neq \llbracket \mathrm{nP}_{2} \rrbracket$. (This requirement is implemented by the presence of the E-feature, but any equivalent identity condition on ellipsis will have the same effect, given the structures posited; see Johnson 2013 for a recent alternative.)

Instead, the proform analysis is required here. Recall from (41a) that dhaskalos has no gender presupposition, while, as given in (41b), dhaskala does. Since dhaskalos itself has no gender presupposition, it can supply the meaning of $e_{N}$ even when this latter is in an environment normally requiring the other gender:

$$
\llbracket e_{N 2} \rrbracket^{g}=g(2)=\llbracket \text { dhaskalos }_{2} \rrbracket^{g}=\lambda x . t e a c h e r(x) \text { (by (49), (51), (41a)) }
$$

The correct structure therefore, given in (55), has $e_{N}$ as the complement of Num and no gender specification inside the DP at all (since $e_{N}$ is in the structural position normally occupied by Gender, under Num). The local gender specifications on the determiner and adjective inside the DP cannot, therefore, be supplied by the usual route (agreement with Gender or the noun). They are instead supplied via Agree with the subject, not with $e_{N}$ (which itself has no gender feature) ${ }^{18}$.

\footnotetext{
${ }^{18}$ See Baker 2008 for a theory that allows upward agreement in such cases (where the usual, closer controller is missing), and Wurmbrand 2011 for a detailed examination of the consequences of such a theory.
} 
(55)

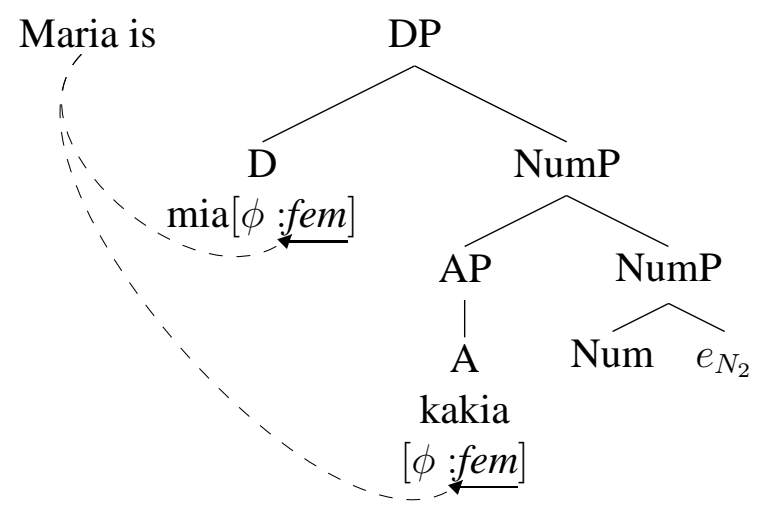

The reverse alternation, with a feminine antecedent and an elided masculine, has no licit derivation. The proform $e_{N}$ will be of no use, as given in (56a), since it would derive the anomalous result that Petros is a female: the antecedent to $e_{N}$, namely dhaskala, does have a lexically specified presupposition, which is therefore assigned by the assignment function as the meaning of $e_{N}$ in this context given the indicated indexing. This is shown in (56b).

(56) As predicates $(f \nrightarrow m)$ :

a. \# I Maria ine kali dhaskala ${ }_{2}$, ala o Petros ine enas the Maria is good.fem teacher.fem but the Petros is a.masc

kakos $e_{N 2}$.

bad.masc

'Maria is a good teacher, but Petros is a bad one.'

b. $\llbracket e_{N 2} \rrbracket^{g}=g(2)=\llbracket$ dhaskala ${ }_{2} \rrbracket^{g}=\lambda x: x$ is female $[$ teacher $(x)]$ (by (49), (51), (41b))

And the PF-deletion option is of no use here, for the same reason it can't be used to derive $m \rightarrow f$ examples such as (53a): ellipsis requires identity, and $\llbracket \mathrm{nP}_{1} \rrbracket \neq \llbracket \mathrm{nP}_{2} \rrbracket$.

Attributive elements such as determiners and adjectives when used in a predicate nominal have two possible controllers for their agreement features in this theory: the usual local, 'concord' controller-the head noun-, which must be agreed with when present, and the subject of the predication itself, which is only an option when the head noun is absent. In argument position, however, this second option will not be available.

A correct result of this system is that neither strategy will apply in cases of gender mismatches in argument positions, such as the pairs in (57a,b). 


\section{(57) As arguments:}

a. * O Petros exi enan dhaskalo stin Veria, ala dhen exi mia the Petros has a.masc teacher.m in.the Veria but not has one.fem stin Katerini.

in.the Katerini

('Petros has a (male) teacher in Veria, but he doesn't have one (female teacher) in Katerini.')

b. * O Petros exi mia dhaskala stin Veria, ala dhen exi enan the Petros has a.fem teacher in.the Veria but not has one.masc

stin Katerini.

in.the Katerini

('Petros has a (female) teacher in Veria, but he doesn't have one (male teacher) in Katerini.')

The PF-strategy fails to work for reasons we have just seen: the ellipsis targets a constituent containing Gender, forcing equivalence. But the proform strategy is equally unsuccessful, because the needed values for the unvalued $\phi$-features on the determiner, etc., cannot be supplied: there is no available accessible controller for the agreement targets. Under this analysis, the object DP containing the missing noun in (57a) would have the structure given in (58).

...*but he doesn't have

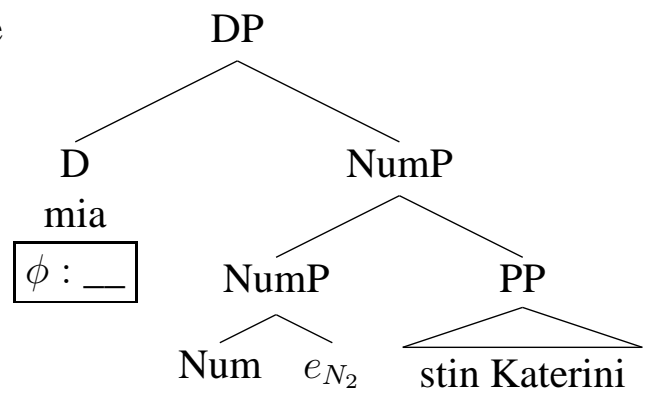

This structure is ill-formed: D's $\phi$-feature is an obligatorily controlled agreement target that lacks the an agreement controller. In the implementation found in Distributed Morphology, the unvalued $\phi$ : on D leads to a Morphology crash: Lexical Insertion cannot occur, and derivation fails to converge.

If it were possible to use the proform without also introducing any element such as a determiner that requires an agreement controller, we would expect that such uses would be licit. It is, however, impossible to find such a context, because 
$e_{N}$ itself requires a licensor-that is, $e_{N}$ can only occur in certain contexts, namely those in which it is in a local relation to an appropriate D, where 'local' means in the same extended projection (see Kester 1996 and Lobeck 2006 for discussion of this requirement). The only possible candidate for the relevant structure is one using bare plurals, which in Greek do not require an overt article; such examples do not permit a gender-mismatched reading.

(59) O Petros exi dhaskales stin Veria, ala dhen exi stin Katerini. the Petros has teachers.fem in.the Veria but not has in.the Katerini only: 'Petros has (female) teachers in Veria, but he doesn't have any (female teachers) in Katerini.'

$\neq$ 'Petros has (female) teachers in Veria, but he doesn't have any (male teachers) in Katerini.'

This is expected on accounts that posit a null D in such cases (as Giannakidou and Merchant 1997 does), since the gender-matched examples would involve PF-deletion of the identical nP, whose head in turn is the agreement controller for the gender features on the null D. An analysis that did not posit a null D would, presumably, rule out the mismatched reading by some version of an overt recoverability requirement applying to the mismatched gender feature.

The crucial difference between arguments and predicates is that agreement targets in arguments have nowhere else to turn for a controller, whereas in predicates, they have the subject.

\subsubsection{Epicene nouns: both gender values are structurally supplied}

Epicene nouns, lacking presuppositional gender values, should license ellipsis in both mismatched directions; these nouns have lexical entries that are both equivalent to that for dhaskalos just considered. Briefly, then, consider the pair of sentences in (60), given with their structural analyses.

(60) As predicates:

a. O Petros ine kalos jatros $_{2}$, ala i Maria ine mia kakia the Petros is good.masc doctor but the Maria is a.fem bad.fem $e_{N 2}$.

'Petros is a good doctor, but Maria is a bad one.' 
b. I Maria ine kali jatros 2 , ala o Petros ine enas kakos the Maria is good.fem doctor but the Petros is a.masc bad.masc $e_{N 2}$.

'Maria is a good doctor, but Petros is a bad one.'

Both usages of $e_{N}$ are licit, as their anaphoric requirements can be resolved, given the following equivalencies:

$$
\llbracket e_{N 2} \rrbracket^{g}=g(2)=\llbracket j_{\text {atros }} \rrbracket^{g}=\lambda x[\operatorname{doctor}(x)] \quad \text { (by (49), (51), (42)) }
$$

As in (55) above, any gender features on nominal modifiers are valued by the subject: mia and kakia by the subject Maria in (60a); enas and kakos by Petros in (60b).

Epicene nouns likewise fail to license their mismatched counterpart in argument positions in either direction:

(62) As arguments:

a. * O Petros exi enan kalo jatro; dhen exi mia kakia. the Petros has a.m good.m doctor not has a.f bad.f ('Petros has a good (male) doctor; he doesn't have a bad (female) one.')

b. * O Petros exi mia kali jatro; dhen exi enan kako. the Petros has a.f good.f doctor not has a.m bad.m

('Petros has a good (female) doctor; he doesn't have a bad (male) one.')

Using a proform as for the predicates fails to supply the agreement values needed on the determiner and adjective: since there is neither a DP-internal local $\mathrm{nP}$ to act as agreement controller, nor is the subject an appropriate agreement controller, the gender features on the argument-internal agreeing elements fail to be valued. 
(63)

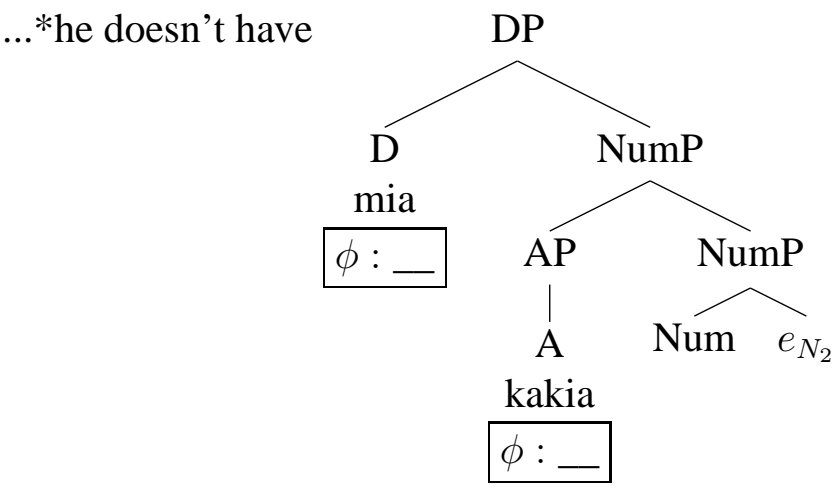

It is now clear why it is crucial that the [E] feature go only on Num, not on Gender. If [E] could delete just NP, excluding nP, we'd expect fully grammatical gender mismatches everywhere, just as we find for number mismatches (see appendix for data). Consider the following hypothetical structures for an argument mismatch case such as (62a):

(64) Peter has

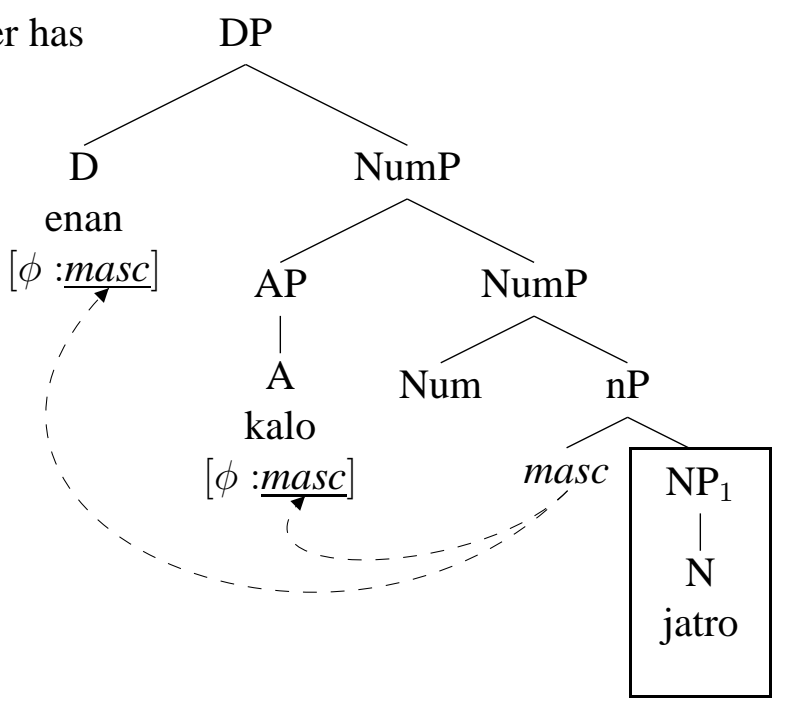

(65) Ineligible low ellipsis: 


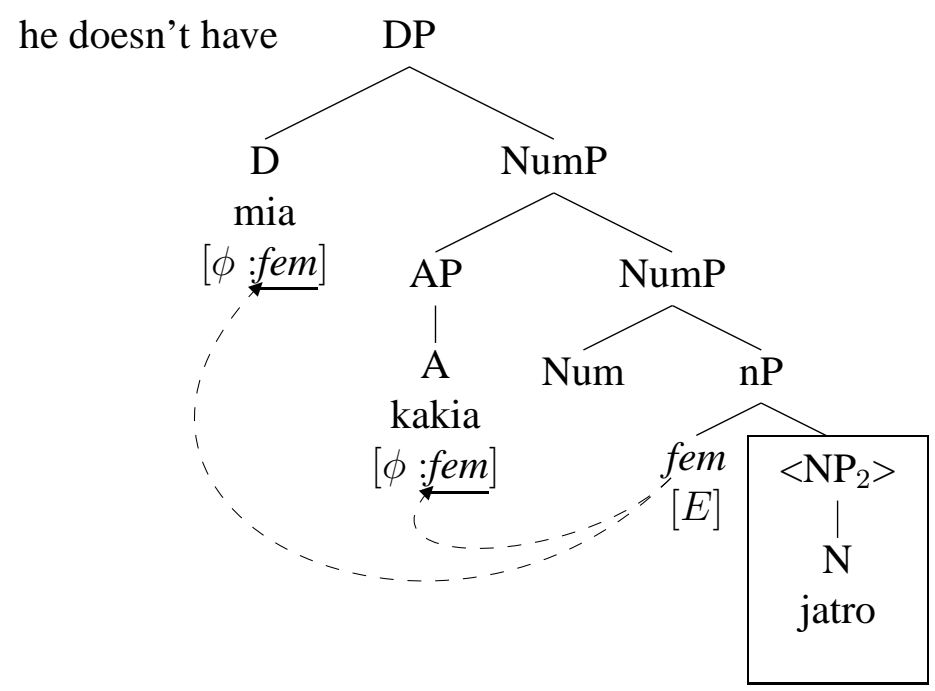

Such a low target for ellipsis must be blocked: allowing NP to be deleted incorrectly predicts gender mismatches such as (62) to be licit, since in (64) $\llbracket \mathrm{NP}_{1} \rrbracket=\llbracket \mathrm{NP}_{2} \rrbracket$ in (65). We therefore conclude that $\mathrm{nP}$ (=GenderP), not NP, is the only target for ellipsis inside the Greek DP.

\subsubsection{Non-alternating nouns: both gender values are presuppositions on $\mathbf{N}$}

The case of non-alternating noun pairs such as adherfos/adherf 'brother/sister' is parallel to the case of dhaskala '(female) teacher' above. In these cases, neither element of the morphological pair can serve as the antecedent to the ellipsis of the other, regardless of direction of mismatch (neither masc $\rightarrow$ fem nor fem $\rightarrow$ masc is possible) and of grammatical role (predicate or argument).

\section{(66) As predicates:}

a. * O Petros ine kalos adherfos, ala i Maria ine mia the Petros is good.masc brother.masc but the Maria is a.fem kakia <adherfi> / $e_{N 2}$.

bad.fem sister

(on the meaning 'Petros is a good brother, but Maria is a bad one (sister).') 
b. * I Maria ine kali adherfi, ala o Petros ine enas the Maria is good.fem sister.fem but the Petros is a.masc kakos <aderfos> / $e_{N_{2}}$.

bad.masc brother

(on the meaning 'Maria is a good sister, but Petros is a bad one (brother).')

These forms cannot be derived by PF-deletion as in the hypothetical pair below:

a. Peter is DP
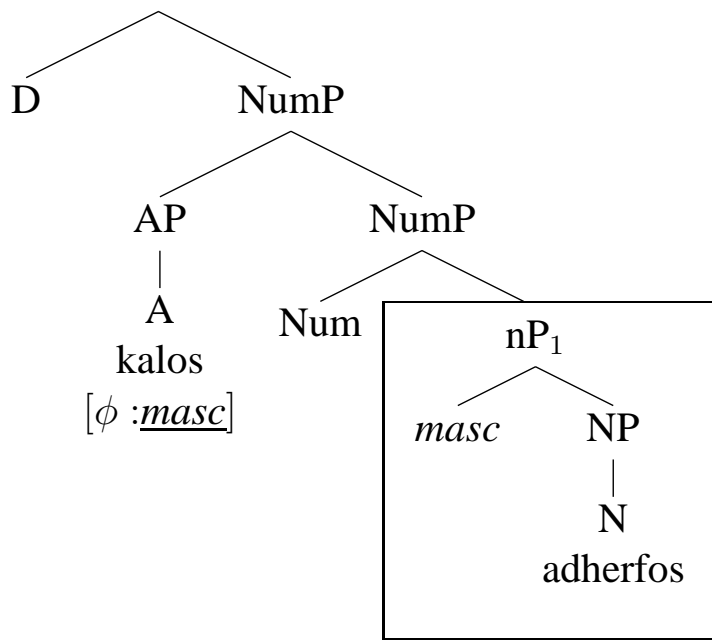

b. Maria is DP

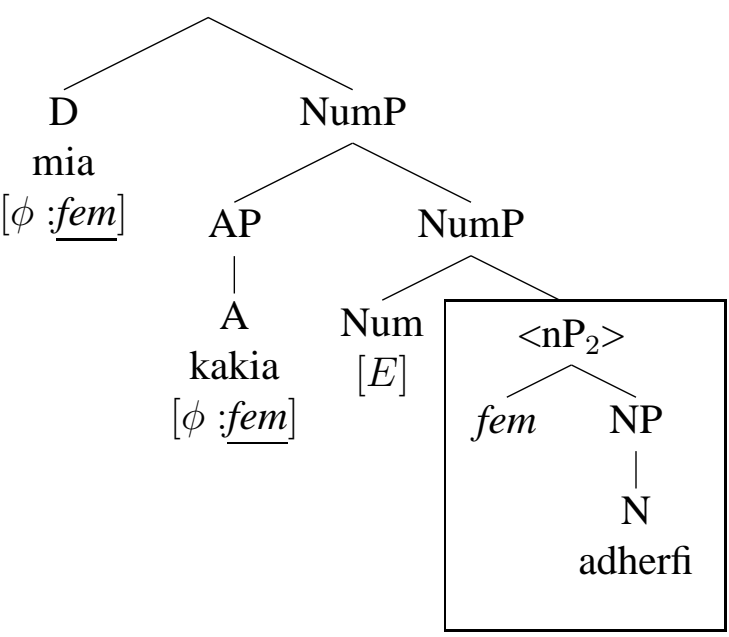


PF-deletion of boxed $\mathrm{nP}_{2}$ in $(67 \mathrm{~b})$ with antecedent $\mathrm{nP}_{1}$ in $(67 \mathrm{a})$ is ruled out because $\llbracket \mathrm{nP}_{2} \rrbracket \neq \llbracket \mathrm{nP}_{1} \rrbracket$ (and indeed $\llbracket$ adherfos $\rrbracket \neq \llbracket$ adherf $\rrbracket$ ).

A derivation employing the proform $e_{N}$ as in (68) is equally unsuccessful, just as it was in (55) above.

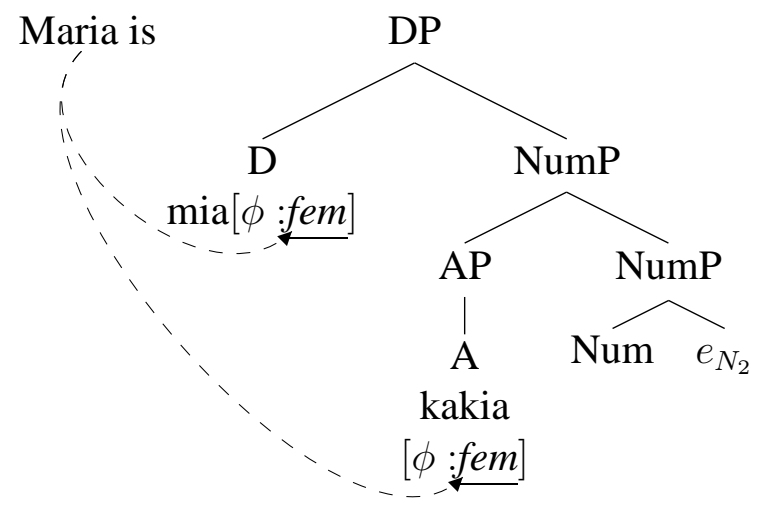

This structure, while it provides a controller for the DP-internal agreeing elements, will only give rise to the presupposition that Maria is a male. The computation of this anomalous result is given in the following:

$$
\llbracket e_{N 2} \rrbracket^{g}=g(2)=\llbracket \text { adherfos }_{2} \rrbracket^{g}=\lambda x: x \text { is a male }[\operatorname{sibling}(x)]
$$

Mismatches in argument positions will fail for the same reasons: the identity condition on PF-deletion cannot be satisfied, and the proform will invariably generate the undesired presupposition, since the gender presuppositions are specified as part of the lexical entries of both nouns.

\subsubsection{Predicate and argument mixed antecedence}

A uniform theory of NP-ellipsis, whether based on PF-deletion, LF-copy ${ }^{19}$, or some other mechanism, would have to postulate that certain values of certain gender features in certain positions, but not in others, could be ignored for the purposes of the computation of the identity or recoverability relation required by ellipsis. One implementation would take the gender features on non-alternating

\footnotetext{
${ }^{19}$ LF-copy theories of ellipsis (see Lobeck 1995, Chung et al. 1995, 2010, Frazier and Clifton, Jr. 2001, Fortin 2007, Li 2010, and others) typically posit at the ellipsis site a designated phonologically null element, labelled pro or $e$, which is replaced after Spell-Out but before LF by a copy of the antecedent, using an operation known as LF-copy.
} 
nouns and on nouns such as adherfi to be 'indelible' and those on the others to be 'delible', allowing the delible values to be erased or ignored under agreement for the purposes of ellipsis. Such an account, whose details I will not attempt to work out here, could capture the basic patterns, but would fail in two areas, if implemented using LF-copy.

The first shortcoming is a familiar one: LF-copy theories have difficult in accounting for the presence of elements that appear to head an unbounded dependency whose gap should be internal to the ellipsis site. An example of such a case was presented above in (44).

A second difficulty comes from cases where a noun is used as predicate and provides the antecedent to an elided noun used as an argument: on the deletionof-features + LF-copy account, such combinations should be impossible. After agreement (deleting the predicate N's gender features), LF-copy of that noun should have no features (this is to allow for gender mismatches). Therefore, such neutered nouns should not be able to be used to resolve ellipsis in argument positions (because in such positions, agreement-dependent elements would go unvalued). It appears, however, that examples with the relevant properties are indeed well-formed (unsurprisingly, gender mismatches are ruled out in such cases as well, since the missing noun is in argument position):

(70) I Seoul ine mia poli me ena metro, ala emis stin Kalifornia dhen the Seoul is a.f city with a subwaybut we in.the California not exume oute mia.

have even one.f.

'Seoul is a city with a subway, but we in California don't have even one. (=city with a subway).'

(71) O Giorgos ine jatros. Dhiladhi, an xriazese enan, milise the Giorgos is doctormasc so if you.need one.masc speak m'afton. with'him

'Giorgos is a doctor. So if you need one, speak with him.'

Such examples are straightforward as examples of PF-deletion on the present heterogeneous account, but tell against a uniform analysis. ${ }^{20}$

\footnotetext{
${ }^{20} \mathrm{~A}$ reviewer points out that the present account also predicts, correctly, that examples such as the following will not be ambiguous. The missing predicate in the first example can only be interpreted as '(is) someone who has a (male) doctor', not '(is) someone who has a (female) doctor', and in the second example, the missing NP can be interpreted only as 'a photograph of a
} 


\subsubsection{Neuter human-denoting nouns}

A final case to consider is when the antecedent of a predicate ellipsis is one of the four neuter nouns mentioned in section 2.2 above which denote humans (pedhi 'child', agori 'boy', koritsi 'girl', melos 'member'). These nouns can serve as antecedents to ellipses, but any modifying elements must be neuter, and cannot agree with the subject's features (given their lexical meanings, the nouns agori and koritsi will not permit gender mismatches in any case):

a. O Petros ine ena kalo melos tu tmimatos, the.masc Petros is a.neut good.neut member.neut of.the department ala i Maria ine ena axristo. but the.fem Maria is a.neut useless.neut 'Petros is a good member of the department, but Maria is a useless one.'

b. * O Petros ine ena kalo melos tu the.masc Petros is a.neut good.neut member.neut of.the tmimatos, ala i Maria ine mia axristi. department but the.fem Maria is a.fem useless.fem ('Petros is a good member of the department, but Maria is a useless one.')

The well-formedness of (72a) is expected. The predicate node $\mathrm{nP}$ (melos tu tmimatos) is headed by an $n$ with the gender feature value neuter, and so is identical to the antecedent $\mathrm{nP}$, permitting ellipsis (assuming that the feature neuter does not contribute anything semantically).

But it is less clear how to block (72b). Something must prevent a structure like the one seen above in (55) from occurring. It would appear that in these cases, the ellipsis analysis is the only one possible: in that case, since the Gender feature in the $\mathrm{nP}$ is present, its features must be used to determine gender agreement inside

(male) doctor', not as the gender-mismatched 'a photograph of a (female) doctor'.

(1) O Kostas ine kapjos pu exi enan jatro, ke o Pavlos (ine) episis. the Kostas is someone who has a doctormasc and the Pavlos is too 'Kostas is someone who has a (male) doctor, and Pavlos (is), too.'

(2) Ego exo mia fotografia enos jatru, ke esi exis mia, episis. I have a picture of.a.masc doctormasc and you have one too 'I have a picture of a (male) doctor, and you have one, too.' 
the extended projection of the noun (hence neuter appears on the article and adjectives). The blocking of the otherwise possible pro-form analysis seems to be of a piece with other observations in the literature that when a matching antecedent is available, it must be used, and its availability blocks other strategies from being used (see Merchant 2010 for some examples). But whatever general constraint seems to be in play in this case, it must not prevent the well-formed mismatches of the dhaskalos/jatros kind seen above. One possibility would be to attribute the ill-formedness of (72b) to a feature interpretation clash: if the valued gender features on the attributive adjective and determiner are interpreted, and if the resulting value of the pro-form $e_{N}$ were incompatible with those interpretations, the structure would be blocked. This possibility is, however, counter to the intuition that the neuter feature on nouns such as pedhi is not interpreted, and indeed the noun should not be restricted to denote only in the set of non-male and non-female entities (since this would mean the noun could not in fact denote humans). One possibly relevant observation is that while even in the unacceptable cases of mismatches seen in the previous sections there is at least the possibility of an overt, deaccented, grammatical continuation (as demonstrated in (33)-(35)), with (72b) there is no possible grammatical overt continuation: $*_{i}$ Maria ine mia axristi melos (the Maria is a.fem useless.fem member.neut). How to make the availability of the pro-form sensitive to this fact remains unclear, unless the gender feature has a different form on such nouns (for example, if the neuter value were 'indelible' and agreement were imposed also at LF or wherever the anaphora is resolved).

Since there are serious unanswered questions about how gender on such nouns should be represented and interact with the overall system, it is not clear whether these facts pose a direct difficulty for the present or related accounts (see Pesetsky 2012 and Matushansky 2013 for relevant discussion of related facts from Russian: unlike Russian, however, Greek does not allow for partial mismatches within the NP or clause).

\section{Conclusions}

The examination of the variable behavior of gender features under nominal ellipses in Greek has led to the discovery of three classes of nouns, parallel in kind to those identified in earlier literature on the Romance languages: those that permit no gender mismatches under predicate ellipsis, those that permit gender mismatches in either direction, and those that permit mismatches only in one direction 
(masculine antecedents for elided feminines). ${ }^{21}$ These gender features are different in behavior from number features, which show no such class behavior, permitting mismatches uniformly (see appendix for data). A further asymmetry was shown to exist: no nouns permit gender mismatches when in argument positions.

These data can be captured by positing that gender features on nouns denoting humans are interpretable, but vary in where they appear in the structure: some nouns (adherfos, adherfi, dhaskala) have gender presuppositions as part of their lexical meanings, while others (dhaskalos, jatros) get their presuppositions only as a result of combining with a Gender node in the syntax (whose value for gender is also interpretable). With these analytical pieces in place, the ellipsis facts were shown to be amenable to a treatment in a heterogeneous theory of null things that employs both PF-deletion ('ellipsis' or 'surface' anaphora) of nP (below number but including gender) and null proforms ('model-theoretic anaphora' or 'deep' anaphora) (see also Merchant 2010, 2013b, Baltin 2012, Miller and Pullum 2013, and Bentzen et al. 2013 for recent discussions of the surface/deep distinction).

This investigation has been built around a certain restricted data set, collected in depth for only a few items from a few speakers. ${ }^{22}$ These data were accounted for with a certain set of formal devices which consist of discrete operations on discrete feature structures. The next step should be a larger and systematic collection of data from more items under more conditions. Such an investigation may reveal that the currently described patterns hold in a larger sample, or may reveal a more nuanced, gradient set of facts. If the latter, we may want to consider either other modes of explanation (making these null nominals' availability contingent on other aspects of the cognitive representation of their antecedents, including potentially idiosyncratic facts of their histories of use) or making the formal devices more sensitive to variation, as has been explored recently by Adger and Smith 2010 and others. Both possibilities hold promise for deepening our understanding of the nature of gender and other features.

\footnotetext{
${ }^{21}$ Why the fourth possible pattern (pairs of nouns in which the feminine licenses ellipsis of the masculine, but not vice versa) is not attested remains unexplained in formal terms; though it seems reasonable to look for an explanation in terms of markedness, such an examination awaits another occasion.

${ }^{22}$ Andrés Saab points out to me that one should also examine the behavior of 'pro-predicates' such as 'be/do the same (thing)', Spanish ser/estar lo mismo, Greek ine/kano to idhio, which appear to display substantially parallel behavior. See especially Hardt et al. 2011 for recent discussion.
} 


\section{References}

Adger, David, and Jennifer Smith. 2010. Variation in agreement: A lexical feature-based approach. Lingua 120:1109-1134.

Aelbrecht, Lobke. 2010. The syntactic licensing of ellipsis. Amsterdam: John Benjamins.

Aikhenvald, Alexandra. 2000. Classifiers: A typology of noun categorization devices. Oxford: Oxford University Press.

Alexiadou, Artemis, and Kirsten Gengel. 2012. NP ellipsis without focus movement/projections: the role of classifiers. In Contrast and positions in information structure, ed. Ivona Kučerová and Ad Neeleman, 177-205. Cambridge: Cambridge University Press.

Alexiadou, Artemis, Liliane Haegeman, and Melita Stavrou. 2007. Noun phrase in the generative perspective. Berlin: Mouton de Gruyter.

Alsina, Alex, and Boban Arsenijevic. 2012. The two faces of agreement. Language 88:369-380.

Baker, Mark C. 2008. The syntax of agreement and concord. Cambridge: Cambridge University Press.

Baltin, Mark. 2012. Deletion vs. pro-forms: an overly simple dichotomy? Natural Language and Linguistic Theory 30:381-423.

Barbiers, Sjef. 2005. Variation in the morphosyntax of ONE. The Journal of Comparative Germanic Linguistics 8:159-183.

Bentzen, Kristine, Peter Svenonius, and Jason Merchant. 2013. Deep properties of surface pronouns: Pronominal predicate anaphors in Norwegian and German. Journal of Comparative Germanic Linguistics (to appear).

Bernstein, Judy B. 1993. Topics in the syntax of nominal structure across Romance. Doctoral Dissertation, City University of New York.

Bobaljik, Jonathan David. 2008. Where's phi? Agreement as a post-syntactic operation. In Phi theory: Phi-features across modules and interfaces, ed. Daniel Harbour, David Adger, and Susana Béjar, 295-328. Oxford: Oxford University Press.

Bobaljik, Jonathan David, and Cynthia Levart Zocca. 2010. Gender markedness: The anatomy of a counter-example. Morphology 21:141-166.

Brucart, José M. 1987. La elision sintactica en español. Bellaterra: Publicacions de la Universitat Autonoma de Barcelona.

Brucart, José M. 1999. La elipsis. In Gramática descriptiva de la lengua española, ed. Ignacio Bosque and Violeta Demonte. Madrid: Espasa Calpe.

Chomsky, Noam. 1965. Aspects of the theory of syntax. Cambridge, Mas- 
sachusetts: MIT Press.

Chung, Sandra. 2013. Syntactic identity in sluicing: How much, and why. Linguistic Inquiry 44:1-39.

Chung, Sandra, William A. Ladusaw, and James McCloskey. 1995. Sluicing and Logical Form. Natural Language Semantics 3:239-282.

Chung, Sandra, William A. Ladusaw, and James McCloskey. 2010. Sluicing(:) Between structure and inference. In Representing language: Essays in honor of Judith Aissen, ed. Line Mikkelsen, Eric Potsdam, and Rodrigo GutiérrezBravo. Santa Cruz, Calif.: Linguistics Research Center Publications.

Collins, Chris, and Paul M. Postal. 2011. Imposters. Cambridge, Mass.: MIT Press.

Cooper, Robin. 1983. Quantification and syntactic theory. Dordrecht: Reidel.

Corbett, Greville. 1991. Gender. Cambridge: Cambridge University Press.

Cornilescu, Alexandra, and Alexandru Nicolae. 2012. Nominal ellipsis as definiteness and anaphoricity: The case of Romanian. Lingua 122:1070-1111.

Corver, Norbert, and Marjo van Koppen. 2010. Ellipsis in Dutch possessive noun phrases: A micro-comparative approach. Journal of Comparative Germanic Linguistics 13:99-140.

Corver, Norbert, and Marjo van Koppen. 2011. NP-ellipsis with adjectival remnants: a micro-comparative perspective. Natural Language and Linguistic Theory $29: 371-421$.

van Craenenbroeck, Jeroen. 2010. The syntax of ellipsis: Evidence from Dutch dialects. New York, NY: Oxford University Press.

van Craenenbroeck, Jeroen, and Anikó Lipták. 2006. The crosslinguistic syntax of sluicing: Evidence from Hungarian relatives. Syntax 9:248-274.

van Craenenbroeck, Jeroen, and Jason Merchant. 2013. Elliptical phenomena. In The Cambridge handbook of generative syntax, ed. Marcel den Dikken, 14271520. Cambridge University Press.

Craenenbroeck, Jeroen van. 2012. Ellipsis, identity, and accommodation. Ms. Hogeschool-Universiteit Brussel.

Déchaine, Rose-Marie, and Martina Wiltschko. 2010. When and why can 1st and 2nd person pronouns be bound variables? Ms., University of British Columbia.

Depiante, Marcela A., and Jorge Hankamer. 2008. La condición de identidad en la elipsis: El caso del truncamiento. Ms., Universidad Nacional del Comahue and University of California, Santa Cruz.

Depiante, Marcela A., and Pascual José Masullo. 2001. Género y número en la elipsis nominal: Consecuencias para la hipótesis lexicalista. Paper presented at the 1st Encuentro de Gramática Generativa. 
Dowty, David, and Pauline Jacobson. 1989. Agreement as a semantic phenomennon. In Proceedings of the Eastern States Conference on Linguistics (ESCOL) 1988, ed. Joyce Powers and Kenneth de Jong, 95-101. Ithaca, NY: Cornell University, CLC Publications.

Eguren, Luis. 2010. Contrastive focus and nominal ellipsis in Spanish. Lingua 120:435-457.

Fortin, Catherine. 2007. Indonesian sluicing and verb phrase ellipsis: Description and explanation in a minimalist framework. Doctoral Dissertation, University of Michigan, Ann Arbor.

Frazier, Lyn, and Charles Clifton, Jr. 2001. Processing coordinates and ellipsis: Copy $\alpha$. Syntax 8:121-174.

Giannakidou, Anastasia. 2001. The meaning of free choice. Linguistics and Philosophy 24:659-735.

Giannakidou, Anastasia, and Jason Merchant. 1997. On the interpretation of null indefinite objects in greek. Studies in Greek Linguistics 18:141-154.

Giannakidou, Anastasia, and Monika Rathert, ed. 2009. Quantification, definiteness, and nominalization. Oxford: Oxford University Press.

Giannakidou, Anastasia, and Melita Stavrou. 1999. Nominalization and ellipsis in the Greek DP. The Linguistic Review 16:295-331.

Günther, Christine. 2012. The elliptical noun phrase in English: Structure and use. New York: Routledge.

Hankamer, Jorge, and Ivan A. Sag. 1976. Deep and surface anaphora. Linguistic Inquiry 7:391-428.

Hardt, Dan, Line Mikkelsen, and Bjarne Ørsnes. 2011. Orphans hosted by VP anaphora. In Proceedings of WCCFL, the Arizona meeting. Cascadilla Press.

Heim, Irene. 2008. Features on bound pronouns. In Phi theory: Phi-features across modules and interfaces, ed. Daniel Harbour, David Adger, and Susana Béjar, 35-56. Oxford: Oxford University Press.

Heim, Irene, and Angelika Kratzer. 1998. Semantics in generative grammar. Malden, MA: Blackwell.

Johnson, Kyle. 2001. What VP ellipsis can do, and what it can't, but not why. In The handbook of contemporary syntactic theory, ed. Mark Baltin and Chris Collins, 439-479. Oxford: Blackwell Publishers.

Johnson, Kyle. 2013. Recoverability of deletion. Ms., University of Massachusetts, Amherst.

Kester, Ellen-Petra. 1996. The nature of adjectival inflection. Utrecht: LEd.

Kobele, Gregory M. 2012. Eliding the derivation: A Minimalist formalization of ellipsis. In Proceedings of the HPSG 2012 conference, ed. Stefan Müller. 
Stanford, Calif.: CSLI Publications.

Kornfeld, Laura M., and Andrés L. Saab. 2002. Nominal ellipsis and morphological structure in Spanish. In Romance languages and linguistic theory 2002: Selected papers from Going Romance, ed. Reineke Bok-Benneman, 183-199. John Benjamins.

Kratzer, Angelika. 2009. Making a pronoun: Fake indexicals as windows into the properties of pronouns. Linguistic Inquiry 40:187-237.

Lee, Jackson. 2012. NP ellipsis may not be licensed by Agree. Ms., University of Chicago.

Li, Yen-hui Audrey. 2010. Born empty. Ms., University of Southern California.

Lipták, Anikó, and Andrés L. Saab. 2011. No head movement inside nominals: Evidence from ellipsis. Ms., Leiden University and University of Comahue.

Lobeck, Anne. 1995. Ellipsis: Functional heads, licensing and identification. New York: Oxford University Press.

Lobeck, Anne. 2006. Ellipsis in DP. In The Blackwell companion to syntax, ed. Martin Everaert, Henk van Riemsdijk, Rob Goedemans, and Bart Hollebrandse, volume 2, chapter 22, 145-173. Blackwell.

Masullo, Pascual José, and Marcela A. Depiante. 2004. Variable vs. intrinsic features in Spanish nominal ellipsis. Ms., University of Pittsburgh and Universidad de Comahue.

Matushansky, Ora. 2013. Gender confusion. In Diagnosing syntax, ed. Lisa LaiShen Cheng and Norbert Corver, 271-294. Oxford: Oxford University Press.

Merchant, Jason. 2009. Phrasal and clausal comparatives in Greek and the abstractness of syntax. Journal of Greek Linguistics 9:134-164.

Merchant, Jason. 2010. Three kinds of ellipsis. In Context-dependence, perspective, and relativity, ed. Francois Recanati, Isidora Stojanović, and Neftalí Villanueva, 1-52. Berlin: Mouton de Gruyter.

Merchant, Jason. 2013a. Diagnosing ellipsis. In Diagnosing syntax, ed. Lisa LaiShen Cheng and Norbert Corver, 537-542. Oxford: Oxford University Press.

Merchant, Jason. 2013b. Revisiting conditions on predicate anaphora. In The core and the periphery: Data-driven perspectives on syntax inspired by Ivan A. Sag, ed. Philip Hofmeister and Elisabeth Norcliffe, 1-4. Stanford, Calif.: CSLI Publications.

Merchant, Jason. 2013c. Voice and ellipsis. Linguistic Inquiry 44:77-108.

Miller, Philip H. 2011. The use of the English verbal anaphor "do so" in discourse: descriptive analysis and theoretical consequences. Paper presented at Typology and Language Universals workshop, University of Paris 7.

Miller, Philip H., and Geoffrey K. Pullum. 2013. Exophoric VP ellipsis. In The 
core and the periphery: Data-driven perspectives on syntax inspired by Ivan A. Sag, ed. Philip Hofmeister and Elisabeth Norcliffe, 5-32. Stanford, Calif.: CSLI Publications.

Nunes, Jairo, and Cynthia Zocca. 2005. Morphological identity in ellipsis. In Leiden working papers in linguistics 2.2, 29-42. Leiden: Leiden University.

Nunes, Jairo, and Cynthia Zocca. 2010. Lack of morphological identity and ellipsis resolution in Brazilian Portuguese. In Minimalist essays on Brazilian Portuguese syntax, ed. Jairo Nunes, 215-236. Amsterdam: John Benjamins.

Panagiotidis, Phoevos. 2002. Pronouns, clitics, and empty nouns. Amsterdam: John Benjamins.

Panagiotidis, Phoevos. 2003a. One, empty nouns and $\theta$-assignment. Linguistic Inquiry 34:281-292.

Panagiotidis, Phoevos. 2003b. Empty nouns. Natural Language and Linguistic Theory 12:381-432.

Payne, John, Geoffrey K. Pullum, Barbara C. Scholz, and Eva Berlage. 2013. Anaphoric one and its implications. Language 89.

Pesetsky, David. 2012. Russian case morphology and the syntactic categories. Ms., MIT.

Picallo, Carme M. 1991. Nominals and nominalizations in Catalan. Probus 3:279_ 316.

Ritter, Elizabeth. 1988. A head-movement approach to construct state Noun Phrases. Linguistics 26:909-929.

Saab, Andrés L. 2008. Hacia una teoría de la identidad parcial en la elipsis. Doctoral Dissertation, University of Buenos Aires.

Saab, Andrés L. 2010. (Im)possible deletions in the Spanish DP. Iberia 2:45-83.

Sag, Ivan A., and Jorge Hankamer. 1984. Toward a theory of anaphoric processing. Linguistics and Philosophy 7:325-345.

Sleeman, Petra. 1996. Licensing empty nouns in French. Holland Institute of Generative Linguistics.

Tasmowski-De Ryk, Liliane, and S. Paul Verluyten. 1981. Pragmatically controlled anaphora and linguistic form. Linguistic Inquiry 12:153-154.

Tasmowski-De Ryk, Liliane, and S. Paul Verluyten. 1982. Linguistic control of pronouns. Journal of Semantics 1:323-346.

de Vaugelas, C. F. 1647. Remarques sur la langue francaise. Paris: Librairie E. Droz, 1934, facsimile edition.

Villavicencio, Aline, Louisa Sadler, and Doug Arnold. 2005. An HPSG account of closest conjunct agreement in NP coordination in Portuguese. In Proceedings of the HPSG05 conference, ed. Stefan Müller. Stanford, Calif.: CSLI Publications. 
Wechsler, Stephen, and Larisa Zlatić. 2003. The many faces of agreement. Stanford, Calif.: CSLI Publications.

Wurmbrand, Susanne. 2011. Syntactic dependencies. Handout, University of Connecticut.

Zamparelli, Roberto. 2008. Bare prediate nominals in Romance languages. In Essays on nominal determination, ed. Henrik Høeg Müller and Alex Klinge, 101-130. Amsterdam: John Benjamins.

\section{Appendix: Number switches}

This paper has concentrated on gender mismatches, as we find variable behavior among the noun classes in this domain. Mismatches in number between the antecedent and elided noun are licit in all three classes, in both directions $\left(s g_{A} \rightarrow p l_{E}\right.$ and $\left.p l_{A} \rightarrow s g_{E}\right)$, as mentioned in passing above and as explored more fully in the literature on these ellipses particularly in Spanish. For completeness, I give in this section representative data from the three nominal classes for predicative and argumental use, showing that number mismatches are tolerated.

\section{Predicates:}

(73) a. O jatros ine prinkipas, ala i dhikigori oxi. the doctor.sg is prince.sg but the lawyers.pl not 'The doctor is a prince, but not the lawyers.'

b. I dhikigori ine prinkipes, ala o Petros oxi. the lawyers are princes but the Petros not 'The lawyers are princes, but not Petros.'

(74) a. O jatros ine jatros, ala i dhikigori oxi. the doctor.sg is doctor.sg but the lawyers.pl not 'The doctor is a doctor, but not the lawyers.'

b. I dhikigori ine jatri, ala o Petros oxi. the lawyers are doctors but the Petros not 'The lawyers are doctors, but not Petros.'

(75) a. O jatros ine dhaskalos, ala i dhikigori oxi. the doctor.sg is teacher but the lawyers.pl not 'The doctor is a teacher, but not the lawyers.'

b. I dhikigori ine dhaskali, ala o Petros oxi. the lawyers are teachers but the Petros not 
'The lawyers are teachers, but not Petros.'

\section{Arguments:}

(76) a. O Petros exi enan adherfo stin Veria, ke dhio stin Katerini. the Petros has one brother in.the Veria and two in.the Katerini 'Petros has one brother in Veria, and two in Katerini.'

b. O Petros exi dhio adherfus stin Veria, ke enan stin Katerini. the Petros has two brothers in.the Veria and one in.the Katerini 'Petros has two brothers in Veria, and one in Katerini.'

(77) a. O Petros exi enan jatro stin Veria, ke dhio stin Katerini. the Petros has one doctor in.the Veria and two in.the Katerini 'Petros has one doctor in Veria, and two in Katerini.'

b. O Petros exi dhio jatrus stin Veria, ke enan stin Katerini. the Petros has two doctors in.the Veria and one in.the Katerini 'Petros has two doctors in Veria, and one in Katerini.'

(78) a. O Petros exi enan dhaskalo stin Veria, ke dhio stin Katerini. the Petros has one teacher in.the Veria and two in.the Katerini 'Petros has one teacher in Veria, and two in Katerini.'

b. O Petros exi dhio dhaskalus stin Veria, ke enan stin Katerini. the Petros has two teachers in.the Veria and one in.the Katerini 'Petros has two teachers in Veria, and one in Katerini.' 